\title{
The unfoldomics decade: an update on intrinsically disordered
} proteins

\author{
A Keith Dunker*1, Christopher J Oldfield ${ }^{2}$, Jingwei Meng3, Pedro Romero², \\ Jack Y Yang ${ }^{3}$, Jessica Walton Chen ${ }^{2}$, Vladimir Vacic ${ }^{2}$, Zoran Obradovic ${ }^{4}$ and \\ Vladimir N Uversky*5,6,7
}

\begin{abstract}
Address: ${ }^{1}$ Center for Computational Biology and Bioinformatics, Indiana University Schools of Medicine and Informatics, Indianapolis, IN 46202, USA, ${ }^{2}$ Center for Computational Biology and Bioinformatics, Indiana University School of Informatics, Indianapolis, IN 46202, USA, ${ }^{3}$ Department of Biochemistry and Molecular Biology, Indiana University School of Medicine, Indianapolis, IN 46202, USA, ${ }^{4}$ Center for Information Science and Technology, Temple University, Philadelphia, PA 19122, USA, 5 Center for Computational Biology and Bioinformatics, Department of Biochemistry and Molecular Biology, Indiana University School of Medicine, Indianapolis, IN 46202, USA, ${ }^{6}$ Institute for Intrinsically Disordered Protein Research, Indiana University School of Medicine, Indianapolis, IN 46202, USA and ${ }^{7}$ Institute for Biological Instrumentation, Russian Academy of Sciences, 142290 Pushchino, Moscow Region, Russia

Email: A Keith Dunker* - kedunker@iupui.edu; Christopher J Oldfield - cjoldfie@iupui.edu; Jingwei Meng - mengj@iupui.edu; Pedro Romero - promero@compbio.iupui.edu; Jack Y Yang - jyang@bwh.Harvard.edu; Jessica Walton Chen - jchen@jcvi.org; Vladimir Vacic - vladimir@vacic.org; Zoran Obradovic - zoran@ist.temple.edu; Vladimir N Uversky* - vuversky@iupui.edu

* Corresponding authors
\end{abstract}

from IEEE $7^{\text {th }}$ International Conference on Bioinformatics and Bioengineering at Harvard Medical School Boston, MA, USA. 14-17 October 2007

Published: 16 September 2008

BMC Genomics 2008, 9(Suppl 2):SI doi:10.1 I86/I47I-2I64-9-S2-SI

This article is available from: http://www.biomedcentral.com/I47I-2I64/9/S2/SI

(c) 2008 Dunker et al; licensee BioMed Central Ltd.

This is an open access article distributed under the terms of the Creative Commons Attribution License (http://creativecommons.org/licenses/by/2.0), which permits unrestricted use, distribution, and reproduction in any medium, provided the original work is properly cited.

\begin{abstract}
Background: Our first predictor of protein disorder was published just over a decade ago in the Proceedings of the IEEE International Conference on Neural Networks (Romero P, Obradovic Z, Kissinger C, Villafranca JE, Dunker AK (1997) Identifying disordered regions in proteins from amino acid sequence. Proceedings of the IEEE International Conference on Neural Networks, I: 90-95). By now more than twenty other laboratory groups have joined the efforts to improve the prediction of protein disorder. While the various prediction methodologies used for protein intrinsic disorder resemble those methodologies used for secondary structure prediction, the two types of structures are entirely different. For example, the two structural classes have very different dynamic properties, with the irregular secondary structure class being much less mobile than the disorder class. The prediction of secondary structure has been useful. On the other hand, the prediction of intrinsic disorder has been revolutionary, leading to major modifications of the more than 100 year-old views relating protein structure and function. Experimentalists have been providing evidence over many decades that some proteins lack fixed structure or are disordered (or unfolded) under physiological conditions. In addition, experimentalists are also showing that, for many proteins, their functions depend on the unstructured rather than structured state; such results are in marked contrast to the greater than hundred year old views such as the lock and key hypothesis. Despite extensive data on many important examples, including disease-associated proteins, the importance of disorder for protein function has been largely ignored. Indeed, to our
\end{abstract}


knowledge, current biochemistry books don't present even one acknowledged example of a disorder-dependent function, even though some reports of disorder-dependent functions are more than 50 years old. The results from genome-wide predictions of intrinsic disorder and the results from other bioinformatics studies of intrinsic disorder are demanding attention for these proteins.

Results: Disorder prediction has been important for showing that the relatively few experimentally characterized examples are members of a very large collection of related disordered proteins that are wide-spread over all three domains of life. Many significant biological functions are now known to depend directly on, or are importantly associated with, the unfolded or partially folded state. Here our goal is to review the key discoveries and to weave these discoveries together to support novel approaches for understanding sequence-function relationships.

Conclusion: Intrinsically disordered protein is common across the three domains of life, but especially common among the eukaryotic proteomes. Signaling sequences and sites of posttranslational modifications are frequently, or very likely most often, located within regions of intrinsic disorder. Disorder-to-order transitions are coupled with the adoption of different structures with different partners. Also, the flexibility of intrinsic disorder helps different disordered regions to bind to a common binding site on a common partner. Such capacity for binding diversity plays important roles in both protein-protein interaction networks and likely also in gene regulation networks. Such disorder-based signaling is further modulated in multicellular eukaryotes by alternative splicing, for which such splicing events map to regions of disorder much more often than to regions of structure. Associating alternative splicing with disorder rather than structure alleviates theoretical and experimentally observed problems associated with the folding of different length, isomeric amino acid sequences. The combination of disorder and alternative splicing is proposed to provide a mechanism for easily "trying out" different signaling pathways, thereby providing the mechanism for generating signaling diversity and enabling the evolution of cell differentiation and multicellularity. Finally, several recent small molecules of interest as potential drugs have been shown to act by blocking protein-protein interactions based on intrinsic disorder of one of the partners. Study of these examples has led to a new approach for drug discovery, and bioinformatics analysis of the human proteome suggests that various disease-associated proteins are very rich in such disorder-based drug discovery targets.

\section{Background}

More than seventy years ago, it was speculated that antibody binding depends on unfolded rather than structured protein [1,2]. Specifically, Linus Pauling suggested that high flexibility enables one antibody molecule to bind to differently shaped antigens. The specific idea was that of conformational selection in which the flexible antibody would randomly fluctuate among the different structures, with binding by a particular antigen selecting the structure that fits from the other conformers among the ensemble [2]. The current body of evidence suggests that there are approximately two broad classes of antibodies, specific and non-specific. The sequence of a highly specific, highaffinity antibody folds into a specific structure that fits with its cognate antigen (with perhaps slight structural shifts of both the antibody and antigen). On the other hand, at least some of the low affinity, nonspecific antibodies contains binding sites that are disordered in isolation but become differently folded when bound to different partners. A recent assembly of structural data on antibody-antigen interactions supports the early conjectures cited above (manuscript in preparation).

More recently, involvement of intrinsic disorder in molecular recognition has been suggested to involve at least two possible mechanisms [3]. Conformational selection, as described by Pauling [2] and later by Karush [4], is the first mechanism. Alternatively, a local part of the binding region could form an interaction followed by concomitant binding and folding over the remainder of the interface [5-7]. While described sometime ago [6], this second mechanism was recently described in terms of folding funnel concepts and called the "fly casting mechanism" [7]. For two recently studied molecular recognition events, experimental evidence has been provided for the latter mechanism $[8,9]$. Both of these recently studied interfaces are fairly large and extend over significant lengths of the intrinsically disordered proteins. Mixed mechanisms of course are possible, with a subregion of the interface interacting via conformational selection, fol- 
might be due in significant degree to the overall size of the interaction surface.

The existence of unstructured, or incompletely structured, proteins under physiological conditions began to be reported almost sixty years ago, with several additional reports in the following decades [4,10-13]. Since the 1970 s, an increasingly strong stream of disordered protein examples has been revealed, and many of these are described in our database of intrinsically disordered proteins $[14,15]$. This database also contains a bibliography that is showing explosive growth, especially over the last few years.

The crowded conditions inside the cell have been suggested to cause intrinsically disordered proteins to fold into 3D structure. To test this possibility, intrinsically disordered proteins were subjected to molecular crowding by adding high concentrations of agents such as glucose. Such in vitro

In-cell NMR experiments indicate that some proteins or protein regions remain unfolded even when crowding occurs inside a cell [18-20]. Another in-cell NMR report [21] involving some of the same authors was later retracted because protein leakage from the cells led to misleading data [22]. The earlier experiments $[18,19]$ may not have suffered from the same leakage problems, which might have been specific for the protein used in the later studies [22]. Overall, these experiments provide additional evidence that intrinsically disordered proteins remain incompletely folded inside the cell, but additional experiments need to be carried out in order to increase confidence in these results.

A number of different terms have been used to describe these proteins, including rheomorphic [23], natively denatured [24], natively unfolded [25], intrinsically unstructured [26], and several variants of disordered [2729]. By now, several reviews on these proteins have appeared $[16,17,30-34]$. We use "intrinsically disordered" to describe all types of incompletely folded proteins and regions, and we use "natively unfolded" or "intrinsically unstructured" to indicate random-coil-like and pre-molten globular forms. Collapsed random coils as recently described for polyQ $[35,36]$ are similar to, if not identical with, the premolten globule form and in our view these structures fit into the "natively unfolded" category. However, there is not a consensus in this field regarding nomenclature, which suggests the need for a disordered protein ontology.

Just as the amino acid sequence codes for protein structure, so might the sequence also code for lack of structure or disorder. Development of a predictor of protein disorder is one way to test the hypothesis that disorder is encoded by the amino acid sequence. Furthermore, study of disorder prediction provides a means to understand "the protein disorder code." For example, Figure 1A shows that "natively unfolded" proteins (a subset of intrinsically disordered proteins that have little or no ordered structure under physiologic conditions and behave as random coils or pre-molten globules [37-39]) are specifically localized within a unique region of charge-hydropathy phase space, indicating that a combination of low overall hydropathy and high net charge represent a unique structural feature of "natively unfolded" proteins [37]. In more general terms, certain amino acid residues have been found to be highly "order-promoting" (namely cysteine, tryptophan, tyrosine, isoleucine, phenylalanine, valine, leucine, histidine, threonine, and asparagine) while others are highly "disorder-promoting" (namely aspartic acid, methionine, lysine, arginine, serine, glutamine, proline, and glutamic acid) [40-42]. These order-inducing and disorder-inducing amino acid trends are further illustrated by Figure 1B, which depicts the relative amino acid compositions of intrinsically disordered regions available in the DisProt database $[15,43]$ in comparison with a set of structured (or ordered) proteins [40]. In this case, these amino acid compositions were compared by means of a profiling approach $[30,44]$.

During the fourth Critical Assessment of Structure Prediction (CASP) experiment, we worked with the meeting organizers to carry out disorder prediction on the various protein targets. This trial was deemed a success (C.J. Brown, unpublished), so disorder prediction was included in the subsequent CASP 5, 6, and 7 experiments [45-47]. Inclusion of disorder prediction in the CASP experiments has stimulated a rapid increase in the number of such predictors, with at least 25 different predictors having been developed by now. A collection of links to many of these is maintained at the Database of Disordered Protein website http://www.disprot.org.

Several disordered protein predictors have been compared in recent publications [40,45-51]. As more disordered proteins have been identified, and as more sophisticated machine learning methods have been applied, the per residue prediction accuracy has risen from $\sim 70 \%$ to $85 \%$. A 

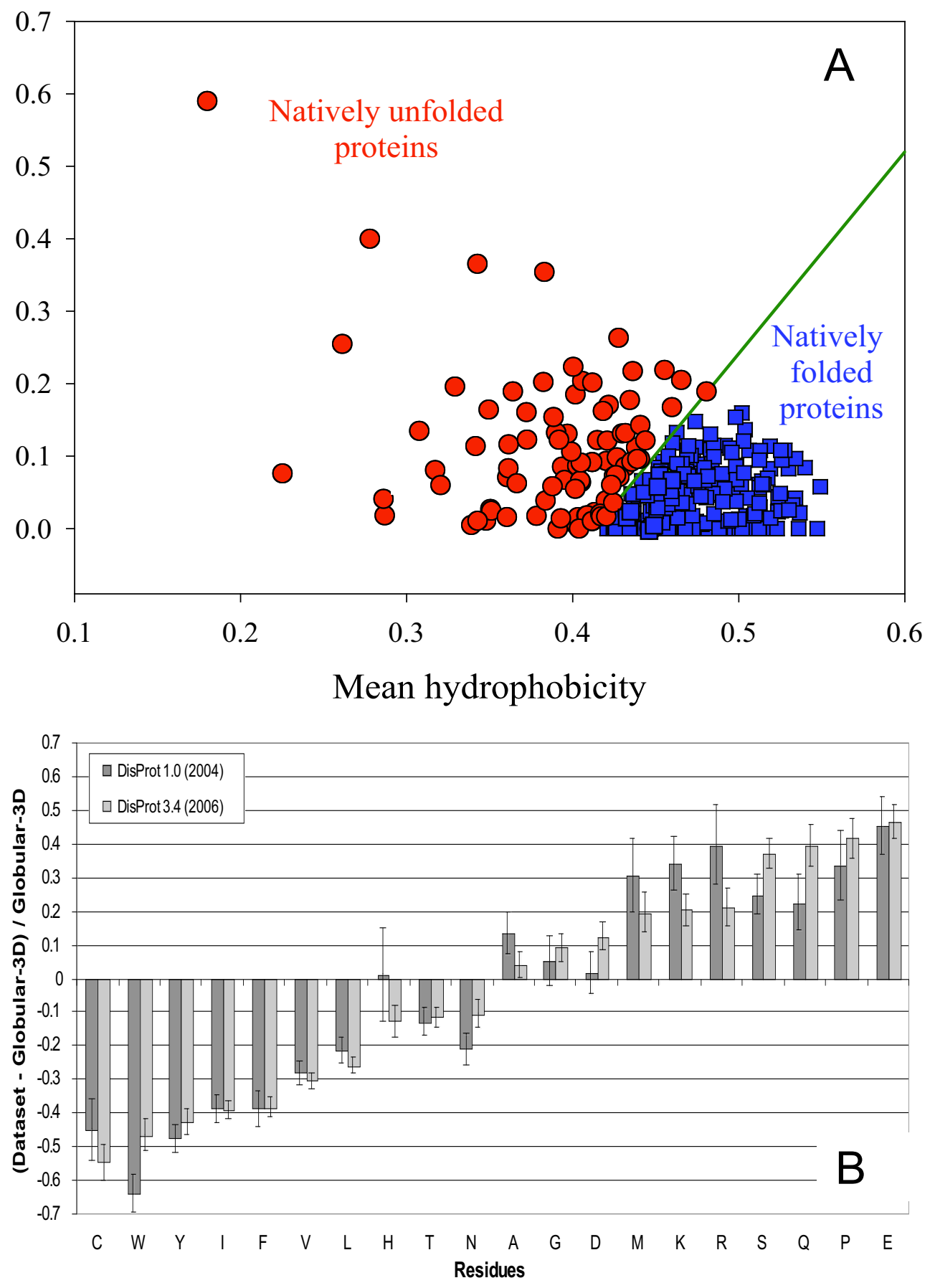

\section{Figure I}

Peculiarities of the amino acid sequences of intrinsically disordered proteins. A. Mean net charge versus mean hydropathy plot (charge-hydropathy plot) for the set of 275 folded (blue squares) and 91 natively unfolded proteins (red circles) [37]. B. Amino-acid composition, relative to the set of globular proteins Globular-3D, of intrinsically disordered regions 10 residues or longer from the DisProt database. Dark gray indicates DisProt I.0 (I 52 proteins), whereas light gray indicates DisProt 3.4 (460 proteins). Amino acid compositions were calculated per disordered regions and then averaged. The arrangement of the amino acids is by peak height for the DisProt 3.4 release. Confidence intervals were estimated using per-protein bootstrapping with 10,000 iterations [40]. 
likely-to-be significant impediment to further improvement is the misclassification of the residues in the training sets.

Application of the disorder predictors to various organisms in the three domains of life, namely, prokaryotes, archaea, and eukaryotes, reveals a large increase in disorder among the eukaryotes compared to the other two types of organisms $[48,52,53]$. One related speculation is that more disorder is needed for signaling and coordination among the various organelles in the more complex eukaryotic domain [54].

The recent explosion of papers on intrinsically disordered protein contains many new discoveries on these proteins by a large number of investigators. There is neither time nor space to adequately cover these important advances. Herein we focus mainly on our own work; and we hope that other researchers in this field will not be offended by this approach. In the following are seven short stories that briefly review recent research on disordered proteins published by our group. These include the following: (1) A bioinformatics study of the relationship between disorder and function in the Swiss Protein Database [55-57]; (2) An introduction of the molecular recognition feature (MoRF) concept and characterization of various MoRFs and MoRF-binding proteins [58-61]; (3) The mechanisms by which one disordered region can bind to many partners and by which many different disordered sequences can bind to one site on one protein partner $[62,63]$ thereby contributing to the complex protein-protein interaction networks that are observed in nature; (4) The observation that regions of mRNA that undergo alternative splicing code for disordered protein much more often than they code for structured protein [64]; (5) A bioinformatics study on conservation of intrinsic disorder in protein domains and protein families $[65,66] ;(6)$ An introduction of the disordered proteins in disease (or $\mathrm{D}^{2}$ ) concept, which is based on bioinformatics analysis that indicate an abundance of intrinsic disorder in diseaserelated proteins [38,67-74]. (7) A novel method for drug discovery based on regions of disordered protein [75]. The novel drug discovery method suggests how the observations in the first six studies might be put to practical use.

\section{Intrinsic disorder and protein function}

Our overall goal is to understand relationships between amino acid sequence and protein function so that, given a new sequence, possible functions could be suggested to interested experimentalists for laboratory testing. For proteins that form 3D structure, this is a well developed problem, but for intrinsically disordered proteins, work on this problem is just beginning. First we will very briefly review function prediction for structured proteins, and then we will compare and contrast the very limited amount of work in this area for intrinsically disordered proteins.

\section{Function prediction for structured proteins}

For structured proteins, sequence homology, if obvious enough, can provide leads regarding protein function [7678]. Attempts to improve sequence matching for function prediction have been carried out [79]. If no suggestive homologue can be found, an alternative approach is to determine the $3 \mathrm{D}$ structure and then to search structure for functional clues, such as residues positioned in space like the same or functionally similar residues in known active sites [80-82]. Often evolution within a family of related proteins can be helpful by means of the evolutionary trace approach [83]. Recent advances have been made in the assessment of binding sites using both structural and sequence homology [84]. For example, in order to create an automated annotation process involving the appropriate knowledge representation and prediction of functionally important residue environments, a method for extraction of features from sequence, sequence alignments, three-dimensional structure, and structural environment conservation in catalytic sites was recently proposed [85]. This tool was used to develop a model for automated identification of catalytic residues in unannotated protein structures. Application of this tool revealed that catalytic residues can be reliably predicted even for enzymes with new folds [85].

\section{Function prediction for disordered proteins}

Our first efforts to associate disorder with function were carried out by manual literature searches. In the development of our protein disorder predictors, we wanted to use disorder characterized by methods other than missing coordinates in X-ray structures, especially to test whether disorder identified by different methods was different at the amino acid sequence level [86]. Therefore, we had accumulated manuscripts describing disordered proteins and regions of disorder characterized by a variety of methods such as NMR, circular dichroism, small angle X-ray scattering, and so on. In addition, we found many examples in which the disorder indicated by missing coordinates in X-ray crystal structures had been confirmed by other methods. Given these proteins and their associated manuscripts, we then carried out literature searches for functions associated with these well studied disordered protein examples. Out of more than 100 disordered proteins and regions, these manual searches identified 27 different functions, and at least one (and commonly more than one) of these functions was found to be associated with $>80 \%$ of the disordered proteins or regions. Of course when a given disordered region or protein has no associated function, it is unclear whether the given disordered protein has no function or whether the function of 
the given disordered protein has simply not yet been found $[87,88]$.

Among the various functions found for disordered regions, even superficial analysis of "natively unfolded" proteins revealed that many of them undergo disorder-toorder transitions when stabilized by binding with specific targets [37]. In fact, for the majority of proteins described in that study, the existence of ligand-induced folding has been established. Examples include induced structure formation upon binding with DNA (or RNA) for protamines, Max protein, high mobility group proteins HMG-14 and HMG-17; osteonectine, SDRD protein, chromatogranins $A$ and $B, \Delta 131 \Delta$ fragment of SNase, and histone H1. Other examples include folding of cytochrome $c$ in the presence of heme, folding of ostecalcine induced by cations, secondary structure formation in parathyroid hormone related protein induced by membrane association, structure formation in glucocorticoid receptor brought about by association with trimethylamine $\mathrm{N}$-oxide, folding of histidine-rich protein II induced by heme; and structure formation and compaction of prothymosin- $\alpha$ mediated by zinc [37]. Therefore, among the major functions of these unstructured, intrinsically disordered proteins are nucleic acid binding, metal ion binding, heme binding and interaction with membrane bilayers [37].

For structured proteins, proteins can be grouped together if they display a common 3D fold as for example in the CATH [89] and SCOP [90] databases. Often these proteins with common folds have recognizable sequence similarity and so can be grouped into evolutionarily-related protein families. Sometimes, proteins have similar folds without recognizable sequence similarity [91].

Sequence matching can be used to group disordered proteins into related sets just as is done for structured proteins. Perhaps because of the absence of structural constraints, however, disordered proteins typically show higher rates of mutations than do structured proteins [88], so it is often more difficult to identify sequence relationships among disordered proteins. The functionally important residues within a disordered region tend to be a small percentage of the total number of residues and so their conservation tends to be obscured because of the mutations of surrounding residues. Given these limitations with regard to sequence matching for disordered proteins, we have tried to develop alternative strategies.

Our attempts to develop clustering algorithms for finding functionally related groups of disordered proteins have yet not been very successful. These failures encouraged us to develop an alternative approach based on predictions of disorder. For this approach, we randomly partitioned a set of disordered proteins into two subsets and developed separate predictors for each group. We then applied the two predictors to all the proteins, and repartitioned the proteins based on which predictor gave the more accurate results. We next retrained the two predictors using the two redistributed sets, and then repeated the competition and the redistribution. We carried out these steps iteratively until the assigned partitions converged. To test for reproducibility, we repeated the original random partition and then repeated the entire experiment several times. The two sets of proteins that resulted were mostly the same for the different initializations, suggesting that the overall approach gives a reproducible partition of the disordered proteins into two groups [92].

Next, we repeated the overall process, but with three subsets, four subsets, five subsets and six subsets instead of two as tried originally. If this approach gives meaningful results, improved agreement between disorder prediction and observation would be expected due to increased homogeneity within each subset. Prediction did improve for the two and three subset partitioning, but not for four, five nor six subset partitioning. We called the three subsets of disordered proteins "flavors." The three subset flavors were labeled V, C and S [92].

The functions associated with the various proteins in each subset were then determined by literature searches. While the different functions did not separate completely among the different subsets, some of these flavors showed a greater tendency to display particular functions, e.g. S was associated with protein binding, $\mathrm{V}$ was associated with RNA binding, and $\mathrm{C}$ was associated with posttranslational modification sites [92].

More work on this approach might lead to improved understanding of the relationships between sequence and function for disordered proteins. To make the original study more manageable, several simplifications were carried out, and these simplifications likely diminished the ability to discriminate different flavors of disorder. Removing these simplifications might enable prediction of function from sequence for at least some regions of disorder. Indeed, using an approach more standard than ours, an important and remarkable success has recently been achieved in the prediction of function from sequence for disordered proteins [93].

More recently we carried out an analysis of the functional annotation over the entire Swiss Protein database from a structured-versus-disordered point of view [55-57]. The first step was to find keywords associated with 20 or more proteins in SwissProt. For each keyword-associated set, one thousand length-matching and number-matching sets of random proteins were drawn from Swiss Prot. Order-disorder predictions were carried out for the key- 
word-associated sets and for the matching random sets. If a function described by a given keyword were carried out by a long region of disordered protein, one would expect the keyword-associated set to have a greater amount of predicted disorder compared to the matching random sets. The keyword-associated set would be expected to have less prediction of disorder compared to the random sets if the keyword-associated function were carried out by structured protein. Given the predictions for the functionassociated and matching random sets, it is possible to calculate the p-values, where a p-value $>0.95$ suggests a disorder-associated function, a p-value $<0.05$ suggests an order-associated function, and intermediate $\mathrm{p}$-values are ambiguous.

Out of 710 keywords each being assigned to at least 20 proteins, 310 had p-values $<0.05$, suggesting order-associated functions, 238 had p-values $>0.95$, suggesting disorder-associated functions, and the remainder, 170, gave intermediate p-values, yielding ambiguity in the likely function-structure associations [55-57].

When the functional keywords were partitioned into

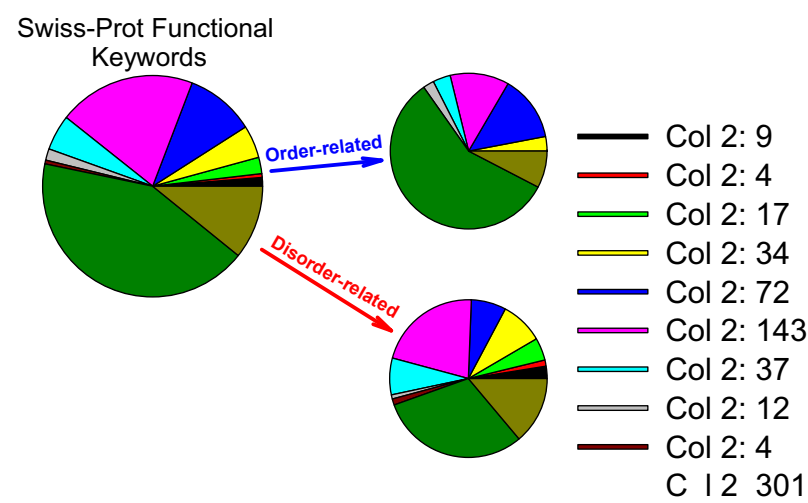

Figure 2

Functional anthology of intrinsic disorder.

eleven functional categories (Biological processes, cellular components, developmental stage, etc.) order-associated keywords were found for seven of the categories, but disorder-associated keywords were found for all eleven categories [55]. This observation supports a previous conjecture that the functional repertoire is larger for disordered proteins compared to that for structured proteins [28]. Figure 2 represents summary of this analysis showing relative distributions of these eleven functional categories among intrinsically disordered and ordered proteins.
Considering the biological processes category, the orderassociated keywords nearly all described processes carried out by (necessarily structured) enzymes (examples: amino acid biosynthesis, purine biosynthesis, lipid synthesis, etc) or by (necessarily structured) integral membrane proteins (electron transport, sugar transport, ion transport). On the other hand, in this same category, the disorderassociated keywords described processes that typically involve control or regulation (differentiation, transcription, cell cycle, growth regulation, etc.). These observations slightly broaden an earlier conjecture that structured proteins are primarily associated with catalysis while disordered proteins are associated with signaling and regulation $[28,94]$.

Finally, it is interesting to compare the individual keywords associated with disorder prediction and with those associated with the absence of disorder prediction (which indicate structure-associated functions). Ribonucleoprotein and ribosomal protein are two disorder-associated keywords with the highest Z-scores (values of 22.1 and 20.6, respectively). Interestingly, the Z-scores drop off to values less than 10 after just a few proteins. Oxidoreductase and transferase are the order-associated keywords with the highest Z-scores (values of -29.5 and -24.5, respectively). Furthermore, the drop-off to values less than 10 occurs more slowly for the order-associated keywords. One possible explanation is that the structured regions for most of the proteins comprise most of the amino acid sequence for the given protein whereas the disordered region might comprise a small part of the entire sequence.

Another interesting feature of these data is that the top 20 order-associated keywords all end in "ase," indicating that all are enzymes of one type or another. This suggests that, for the order-associated keywords, the overall approach works rather well. Although some laboratory genetic engineering experiments have yielded molten globules with enzymatic activity [95], to our knowledge currently known natural enzymes are structured proteins.

Further studies on the disorder-associated key words involved ranking the proteins in each category by Z-score and then carrying out manual literature searches for evidence of association between disorder and function for the highest-ranking proteins. Indeed, for a significant fraction of the high Z-score proteins with functions predicted to be associated with disorder, an association between disorder and function was confirmed by these manual literature searches $[56,57]$.

The tedious work of confirming the associations between disorder and function needs to be carried out for more of the protein groups in this study. It would then be interesting to study these groups of proteins by the methods 
described above or by new methods to find sequencefunction relationships for disorder-associated functions. Such work would provide the basis for enabling researchers to infer (disorder-associated as well as order-associated) function from sequence.

\section{Intrinsically disordered proteins as interactors: MoRFs, linear motifs, "preformed elements" and "fuzzy complexes"}

Protein-protein and protein-nucleic acid interactions, being central to many processes in molecular biology, often involve coupled folding and binding of at least one of the partners and sometimes involve coupled binding and folding for both partners. When a protein-protein interaction involves an intrinsically disordered partner, the methods developed for predicting protein-protein interactions based on known structures are simply not applicable. For intrinsically disordered proteins, new methods and new approaches are needed. The importance of predicting regions of disordered proteins that bind to partners of course depends on the commonness of such proteins.

\section{Finding MoRFs}

We noticed several particular examples in which binding sites within disordered regions coincided with dips in our disorder prediction plots, especially PONDR VL-XT plots [96], so we developed a predictor of binding sites within disordered regions based on disorder prediction [58]. We suggested that these segments contain molecular recognition features or MoRFs. This feature consists of a short region (on the order of 20 residues) that undergoes a disorder-to-order transition that is stabilized by binding to its partner; this short region is within a segment of disorder. These MoRFs were proposed to function in the recognition of protein or nucleic acid partners [58]. Figure 3 shows that a region of hirudin involved in interaction with thrombin has a peculiar and well-recognizable pattern, where short region of predicted order is surrounded by extended regions predicted disorder [73]. This specific pattern was used to develop a unique bioinformatics tool dedicated to the identification of potential protein-protein sites in intrinsically disordered proteins, namely the $\alpha$-MoRF identifier [58]. The application of this identifier to various protein datasets revealed that the frequency of $\alpha$-MoRFs in various types of proteins is highest in those associated with signaling and lowest in the metabolic enzymes. Evidently, these elements have advantages for cell signalling, e.g., allowing among others the decoupling of specificity/affinity, which provides a mechanism by which the strength and duration of signaling events can evolve separately [58].

This first $\alpha$-MoRF identifier was developed using a training data set of a limited size (a set of 13 proteins contain- ing 15 potential $\alpha$-MoRFs). All the training examples were correctly identified by the algorithm, suggesting the possibility of overfitting. Recently, the prediction algorithms was improved by (1) including additional $\alpha$-MoRF examples and their cross species homologues in the positive training set, (2) carefully extracting monomer structure chains from the Protein Data Bank (PDB) as the negative training set, (3) including attributes from recently developed disorder predictors, secondary structure predictions, and amino acid indices, and (4) constructing neural network based predictors and performing validation [61]. The sensitivity, specificity, and accuracy of the resulting predictor, $\alpha$-MoRF-PredII, were $0.87 \pm 0.10,0.87 \pm 0.11$, and $0.87 \pm 0.08$ over 10 cross-validations, respectively [61].

\section{Linear motifs}

A completely different approach for finding protein-protein interaction sites is to search for the few, functionassociated residues that remain conserved in the sea of changes among the surrounding disordered regions. Such conserved residues have been called Eukaryotic Linear Motifs (ELMs) and methods for their discovery from sequence, analogous to finding transcription factor binding sites, have been developed [97-99]. The overall idea is to search for overabundance of particular residues in regions of sequence that lie outside of Pfam domains. The sets of sequences to be tested typically bind to one specific partner. Thus, evidently the conserved residues represent a binding motif within a linker between (Pfam) structured domains or in a disordered tail at the carboxy or amino terminus of a (Pfam) structured domain [99].

Currently, when the search is carried out for ELMs, Pfam domains are excluded. This exclusion typically results in increased focus on regions of intrinsic disorder. However, some Pfam domains contain regions predicted to be disordered with a high degree of conservation [65]. Furthermore, these disordered regions are often implicated in biological functions [66], thus giving a set of disorderassociated functional regions that are not considered by the current ELM analysis. Extending the current ELM analysis to include these Pfam-associated regions of disorder should be done.

ELMs are identified by their over-representation among protein sequences that bind to a common partner [97-99]. Short linear motifs (SLiMs) are also identified as specific sequence patterns that are over-represented in proteins that bind to a common partner, but the algorithms used to discover SLiMs employ filters to remove homologous proteins whereas the ELM-discovery algorithms do not [100]. Thus, ELMs and SLiMs are both identified as sequence patterns in multiple proteins that bind to a common target, with the SLiM-containing set likely to be 


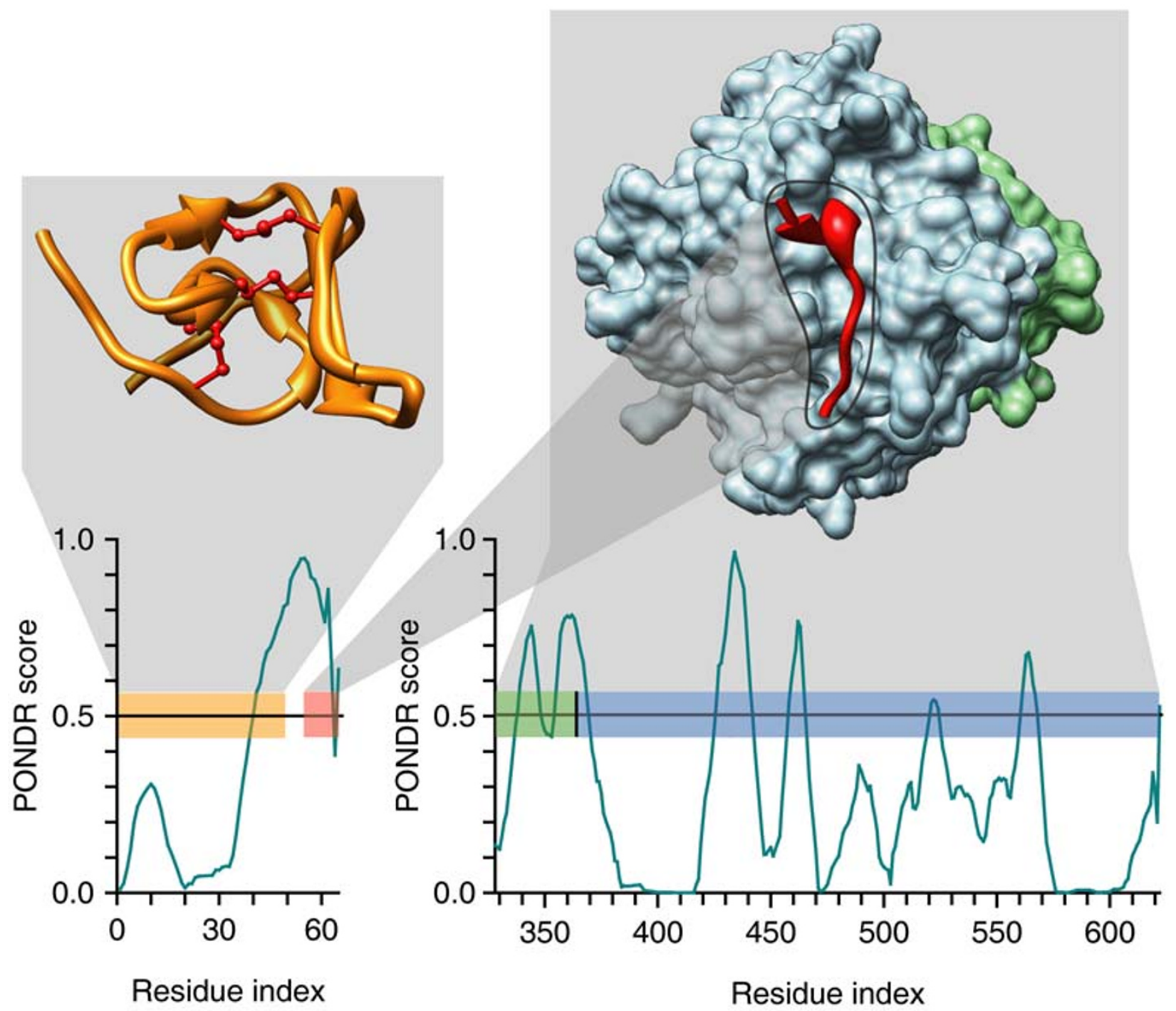

Figure 3

PONDR-based analysis of hirudin and thrombin. The correspondence of PONDR ${ }^{\circledR} V L-X T$ predictions and regions of known structure are shown. Two PDB structures are presented5HIR (left) and $\underline{\text { INO9 }}$ (right) - where each chain is color coded - folded $\mathrm{N}$-terminal domain of hirudin (yellow, disulphide bridges are shown by maroon lines), acidic C-terminal domain of hirudin (red) bound to a heavy chain of thrombin (blue), and light chain of thrombin (green). These color codes are also used for bars in two PONDR ${ }^{\circledR}$ VL-XT plots - (top) hirudin and (bottom) thrombin - to indicate the positions of the regions of known structure in the context of the PONDR ${ }^{\circledR}$ VL-XT predictions. Drawn over these bars, hash marks show the residues in contact with other chains, where the color of the hash mark corresponds to the color code of the chain in contact. Black hash mark in the PONDR ${ }^{\circledR} \mathrm{VL}-\mathrm{XT}$ plot for thrombin corresponds to the factor Xa cleavage site. A predicted $\alpha$-MoRF region of hirudin is shown in corresponding PONDR ${ }^{\circledR} V L-X T$ plot as a pink bar.

entirely nonhomologous but with no such restriction on the ELM-containing set.

MoRFs differ from ELMs and SLiMs in not depending on a specific sequence motif, but rather upon a pattern in a disorder prediction output. Yet, interestingly, recent anal- ysis suggests that linear motifs (LMs) (thus not differentiating between ELMs and SLiMs) show high overlap with MoRFs [101]. Taken all together, these observations suggest that regions of intrinsic disorder often play a role in protein-protein interactions. In addition, there are numerous documented cases where the binding of these disor- 
dered regions is coupled to their folding (reviewed in [102]).

\section{Discriminative features of MoRFs and their binding partners}

Experimentalists have successfully used our MoRF predictors to discover sites of protein-protein interactions that were subsequently confirmed in laboratory experiments $[103,104]$, and other studies independently verified the predicted interactions [105]. Application of this algorithm to databases of genomics and functionally annotated proteins indicates that $\alpha$-MoRFs are likely to play important roles protein-protein interactions involved in signaling events. In agreement with this model, recent computational studies of such binding showed that the disordered partner might contain a "conformational preference" for the structure it will take upon binding, and that these socalled "preformed elements" tend to be helices [58$60,106]$. An important output of induced folding is that this coupled binding and folding determines a unique combination of high specificity and low affinity [107] typical of the signaling and regulation interactions. More recent studies show that at least some disordered regions display template-dependent folding rather than preformed elements (see below, $[62,63]$ ).

A search of PDB has revealed more than 2,500 short regions of one protein (MoRFs) associated with a globular domain of a second protein. Many of these short regions are related to each other, so the number reduces to several hundred families when they are grouped by sequence similarity. Most of these interactions are associated with signaling or regulation [59]. This PDB analysis revealed that MoRFs can be divided into three subtypes according to their structures in the bound state: $\alpha$-MoRFs form $\alpha$-helices, $\beta$-MoRFs form $\beta$-strands, and $\mathrm{l}$-MoRFs form structures without a regular pattern of backbone hydrogen bonds $[59,60]$. We have also found numerous complex MoRFs, which represent mixtures of these three structural forms. Illustrative examples of structurally divergent MoRFs are shown in Figure 4.

Although only a few MoRFs have been studied experimentally, our bioinformatics analysis suggests that all MoRFs are intrinsically disordered in the absence of their binding partners. This was done using the criteria of Gunasekaran et al. [108], who showed that the complexes of intrinsically disordered proteins have much larger interface and surface areas than those of complexes formed by pairs of structured proteins. In other words, Gunasekaran et al. have demonstrated that intrinsic disorder in the unbound state is reflected in the structures of the bound state through relatively large surface and interface areas.
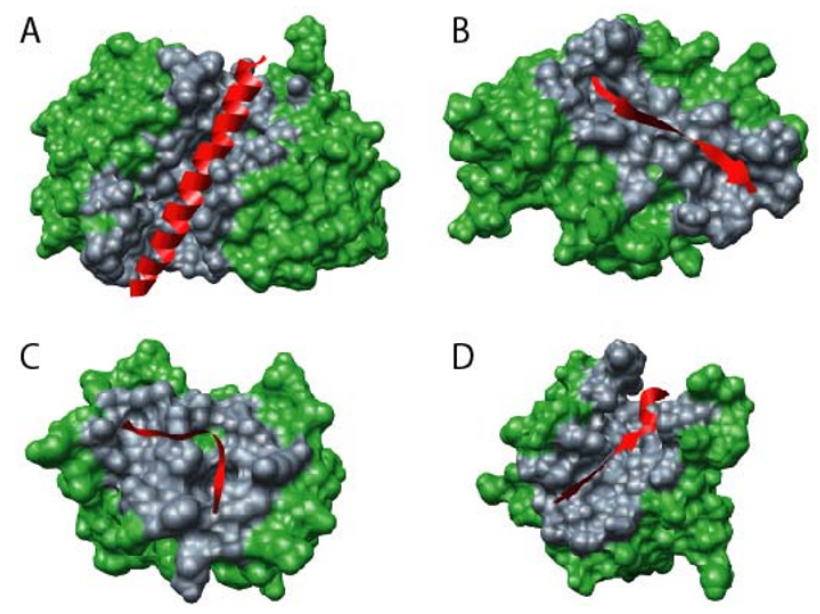

\section{Figure 4}

Examples of structurally divergent MoRFs. MoRFs (red ribbons) and partners (green surface) are shown (A) An $\alpha$ MoRF, Proteinase Inhibitor IA3, bound to Proteinase A (PDB entry IDP5). (B) A $\beta$-MoRF, viral protein pVIc, bound to Human Adenovirus 2 Proteinase (PDB entry $\underline{\text { AVP) }}$. (C) An 1-MoRF, Amphiphysin, bound to $\alpha$-adaptin C (PDB entry IKY7). (D) A complex-MoRF, $\beta$-amyloid precursor protein ( $\beta A P P)$, bound to the PTB domain of the neuron specific protein XII (PDB entry IXII). Partner interfaces (gray surface) are also indicated.

Using the approach and control datasets described above [108], a structural analysis of the bound structures of MoRFs in our dataset of $62 \alpha-, 20 \beta$ - and 176 -MoRF was carried out (Figure 5). Almost all MoRFs in the dataset gave positions above the order-disorder boundary suggested previously, which indicates that these regions are likely to be disordered in isolation, while all ordered proteins gave positions below this boundary, which indicates these proteins are likely to be ordered in isolation [59].

Next, we examined several geometric and physiochemical criteria of MoRF-partner complexes [60]. The comparison of the compositions and physiochemical properties of MoRF and MoRF partner interface residues with the interface residues of homodimers, heterodimers, and antigenantibody complexes indicated that there are significant differences in residue composition and several geometric and physicochemical properties that can be used to discriminate, with a high degree of accuracy, between various interfaces in protein interaction datasets [60].

The MoRF-partner complex formation was shown to be accompanied not only by the binding-induced folding of MoRFs, but also by noticeable structural changes in the MoRF partners which vary widely, from small scale movements to large scale movements and from partial folding 


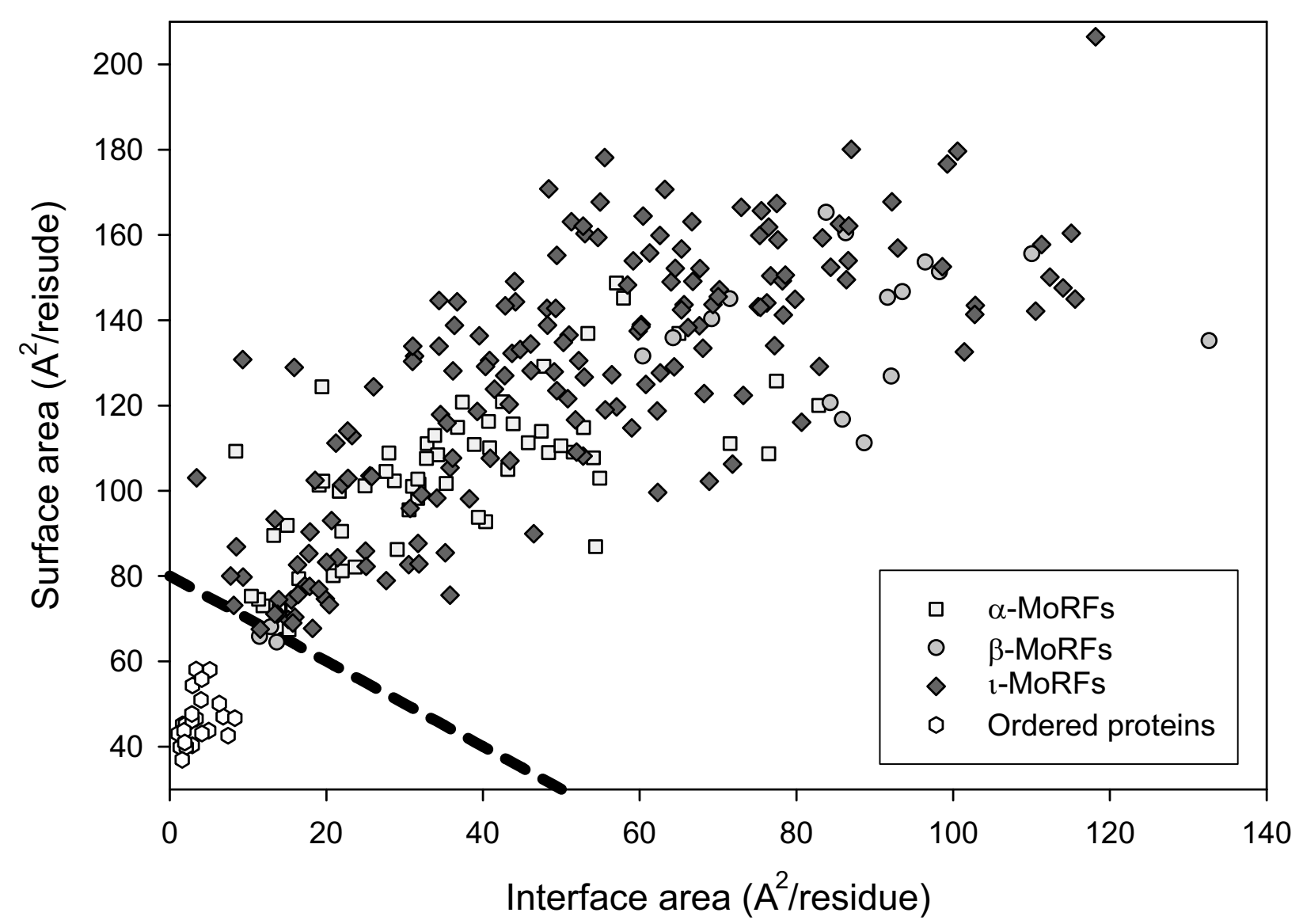

Figure 5

Bioinformatics evidence for the unstructured character of MoRFs in their unbound states. Surface and interface area normalized by the number of residues in each chain for MoRF and the OC datasets.

to partial unfolding [60]. Figure 6 represents several illustrative examples of structural changes induced in MoRF partners by the complex formation. We did not find a single complex that was not accompanied by some structural adjustments in a MoRF partner induced by complex formation [60].

\section{"Fuzzy complexes"}

Recently, it was suggested that intrinsically disordered proteins are able to become ordered following binding to their partner(s) and that this 'restores' the primacy of the classical structure-function paradigm according to which protein function is equated with a well-defined 3D structure [109]. However, the careful analysis of structures of many protein complexes in PDB revealed that this statement is not generally true. In fact, even in the crystal structures, the part(s) of the complexes that contribute productively to binding and function are structurally illdefined, and cannot be described by a single conforma- tional state, in other words demonstrating a significant amount of structural disorder or polymorphism in protein complexes [109]. According to the authors of this study, such disorder can be grouped into four mechanistic categories, where the crucial protein component might adopt a few or multiple alternative conformations ('polymorphic' model), or it might remain disordered but connect ('clamp' model) or neighbour ('flanking' model) ordered binding region(s). At the extreme, the majority or the whole of the bound IDP might remain disordered ('random' model). These observations paved the ground for the "fuzziness" phenomenon according to which functional disorder in protein-protein complexes is widespread covering a continuous spectrum of structural states from static to dynamic disorder and from segmental to full disorder [109]. It has been also argued that fuzziness in protein-protein interactions is beneficial in a variety of functional settings. Its existence, however, has thus far been largely overlooked because of the bias in our experi- 

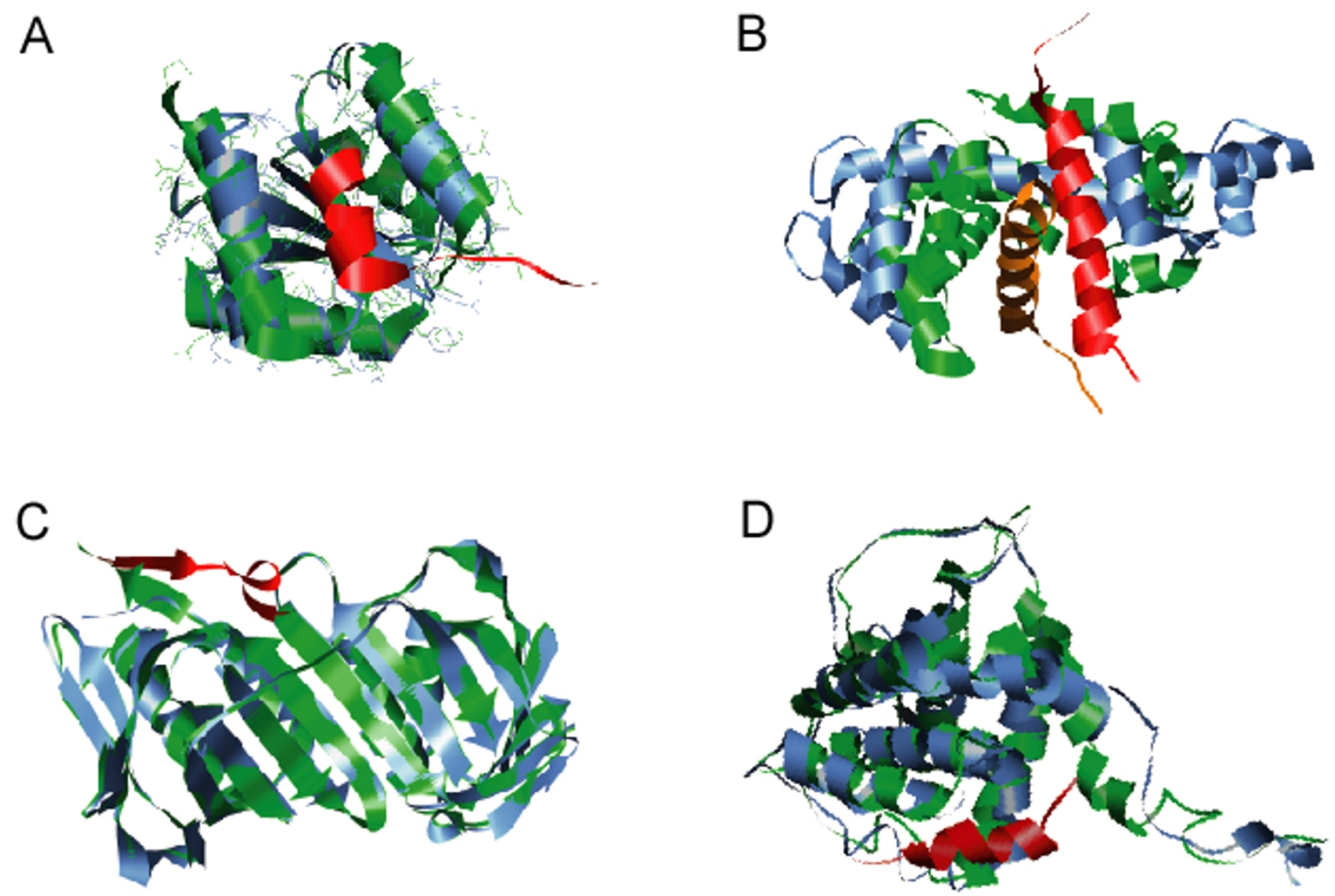

Figure 6

Structural changes in MoRF partners. Ribbon representation MoRF partners shown unbound (blue ribbons) and bound (green ribbons) to MoRFs (red ribbons). (A) Small scale structural alterations in CheY induced by binding of the MoRF region of FliM (PDB entries: unbound - IU8T and bound - IF4V). (B) Large scale structural alterations in calmodulin induced by binding to the MoRF of GAD (PDB entries: unbound - ICLL and bound - INWD). (C) Partial disorder-to-order transition in PCNA induced by binding to the MoRF of FEN-I (PDB entries: unbound - IRWZ and bound - IRXZ). (D) Partial order-todisorder transition in Bcl-xL induced by binding to the MoRF of Bim (PDB entries: unbound - IPQ0 and bound - IPQI).

mental approaches to obtain well-defined structures of complexes, and also with respect to our understanding of the functional relevance of such states [109].

\section{Disordered signalling conduits}

A four-step disordered signalling conduit has been recently proposed to explain the functionality of the cyclin-dependent kinase inhibitor p27 Kip1 (p27) [9]. p27 is a small intrinsically unstructured protein [110] regulating cell proliferation through interactions with cyclindependent kinases (Cdks) [111]. A critical step in the $G_{1}$ to $S$ phase transition of cell division is the phosphorylation-dependent removal of the inhibitory p27 molecule from the surface of the cyclin A/Cdk2 complex. The initial level of p27 in the $G_{1}$ phase is high, and this high level blocks the progression from $G_{1}$ to $S$ phase via the inhibi- tion of Cdk2/cyclin A and Cdk2/cyclin E [112,113]. Therefore, the level of p27 has to decrease significantly for the Cdk2/cyclin complexes to become fully activated and for cell division to progress. The p27 level is controlled via translational regulation and ubiquitination-dependent proteolysis $[114,115]$. Ubiquitination of $p 27$ at the $G_{1} / S$ transition is regulated by its phosphorylation [116]. In addition, abnormal ubiquitination-mediated degradation of p27 is common in human tumors [117].

Recently, a thorough study combined both biophysical and computational tools to reveal a complex four-step conduit model explaining the phosphorylation-mediated dislocation of p27 from cyclinA/Cdk2 [9]. In this model, the starting point is a ternary complex formed between p27 and the cyclin A/Cdk2 heterodimer. In the first step, 
$\mathrm{Y}_{88}$ of p27Kip1 becomes phosphorylated by a non-receptor tyrosine kinase (NRTK), thereby making the Cdk2 active site accessible and leading to the Cdk2-controlled phosphorylation of $\mathrm{p} 27$ at $\mathrm{T}_{187}$. This latter phosphorylation promotes ubiquitination of p27 by the SCFSkp2 $\mathrm{E}_{3}$ lyase complex. Finally, ubiquitinated p27 is degraded by the $26 \mathrm{~S}$ proteasome, activating the cyclin A/Cdk2 complex and promoting the $\mathrm{G} 1$ to $\mathrm{S}$ phase transition [9].

The flexibility and lack of structure are key features for this p27 signaling conduit. The p27 chain encircles the cyclin A/Cdk2 complex and interacts with surface features at several well separated locations [118]. The lack of buried surface area within a single p27 chain in the complex further supports a fully disordered state for unbound p27. Such lack of internal structure facilitates the unzippering of complexes, which allows part of a complex to separate while maintaining other interactions [3]. In the case of $\mathrm{p} 27$, the flexibility allows part of the protein to separate from the surface of the ternary complex while many of the contacts remain intact. The flexibility of the tethered but otherwise free disordered segment further enables p27 to fold back, thereby accelerating phosphorylation via a unimolecular mechanism. The lack of structure also likely facilitates entry of p27 into the proteasome cavity where digestion occurs.

One of the possible explanations for the very complex and highly coordinated four-step signal conduit is that the biology for this particular example requires the disruption of an already-formed complex rather than the inhibition of complex formation [119]. Because of flexibility, the disruption of the $\mathrm{p} 27 / \mathrm{cyclin} \mathrm{A} / \mathrm{Cdk} 2$ complex can proceed in a stepwise, segmental fashion, which likely provides a kinetic advantage for the overall process. By this approach, the interactions are dispersed bit-by-bit rather than all at once [119].

Furthermore, intrinsic disorder in the p27 conduit provides several general features that are useful for signalling interactions such as binding diversity, large interaction surface and uncoupled specificity and affinity. In fact, because a significant part of the binding energy has to be spent to fold a flexible protein, lack of structure and flexibility in the unbound state provide interactions with a mechanism to have both high specificity and low affinity, with the low affinity providing the basis for easy reversibility. On the other hand, a large interaction surface coupled with a high flexibility allows segmental association and dissociation, thereby providing additional opportunities for regulation and control as demonstrated in the conduit model [119].

\section{Intrinsic disorder and protein-protein interaction networks}

Networks linking protein-protein interactions typically involve a few proteins binding to many partners (called hub protein or hubs) and many proteins interacting with just a few partners. How these networks acquired their architecture and how they evolved are both very active areas of research [120-122]. A News and Views article [123], which was longer than the article [124] it discussed, raised the possibility that the ability of hub proteins to bind to many partners might depend on new principles. In essence, the News and Views article raised the question: what feature of protein structure enables binding diversity?

Pauling's 70-year old conjecture that unfolded, dynamic protein ensembles could contribute to binding diversity provided the beginning for the present article. Since Pauling's initial work, several additional researchers have suggested that lack of structure (e.g. disorder) could contribute to the ability of a protein to bind to multiple partners, with several of these researchers providing experimental data in support of this concept $[3,69,125,126]$.

To test the roles of disorder in the specific case of proteinprotein interaction networks, we first collected a set of structurally characterized hub proteins [127]. Several hub proteins were found to be entirely disordered, from one end to the other, and yet to be capable of binding large numbers of partners. Other hubs contained both ordered and disordered regions. For these hubs, many, but not all, of the interactions mapped to the regions of disorder. Two highly structured hubs were found. For both of these structured hubs, 14-3-3 and calmodulin, the binding regions of their partner proteins were found to be intrinsically disordered $[128,129]$. However, it has proven very difficult to globally test whether structured hubs bind to disordered partners. A difficulty with such studies is that the partners often contain both order and disorder, and the disordered regions typically comprise only small fractions of the partner sequences. Thus, without knowing the binding region of each partner, it is difficult to estimate whether or not disorder is involved in any particular interaction.

Overall, our initial study suggested two primary mechanisms by which disorder is utilized in protein-protein interaction networks, namely one disordered region binding to many partners and many disordered region binding to one partner. Several groups have tested these overall ideas further via bioinformatics studies on collections of hub proteins, and these studies support the common use of disordered regions by hub proteins to bind to multiple partners [130-134]. These bioinformatics studies include further refinement of the analysis with the suggestion that 
disorder is very commonly used for regions that bind sequentially to multiple partners (so called "date hubs" [134]).

Without specific regard to protein-protein interaction networks, several years ago we considered possible roles of disorder in protein interactions. In that study, we proposed that "one-to-many" signaling be used to describe the capacity of one disordered region to bind to many partners. We further suggested that "many-to-one" signaling be used to describe how flexibility could enable multiple disordered regions to bind to one site on one partner [3]. While numerous papers suggest that flexibility could enable one protein to bind to many partners, we might have been the first to suggest that flexibility would provide a means for multiple sequences to bind to a common partner.

Recently we studied the detailed structures for a one-tomany example (namely, p53 using its disordered regions to bind to many partners), and we also studied the structures of a many-to-one example (namely, 14-3-3 using its single binding site to associate with many different disordered partners having different amino acid sequences).

Using a collection of structures currently available in the $\mathrm{PDB}$, a single disordered region of p53 is observed to form a helix, a sheet, and two different irregular structures when binding to four different partners, respectively. The set of residues involved in these one-to-many interactions have an identical core set with slightly different extents on either side [62].

The accessible surface area (ASA) with regard to the solvent molecules can be calculated from the three dimensional structure of a protein analytically [135] or numerically [136]. The amount of ASA becoming inaccessible upon complex formation is likewise easily estimated [137] and can be presented as the $\triangle \mathrm{ASA}$.

Plotting the $\triangle \mathrm{ASA}$ versus the sequence position gives a binding profile (Figure 7 ). Interestingly, the single region of p53 bound to four different partners gives completely different binding profiles. For this example, the different partners "read" the same sequence in entirely different ways [62].

For a partner-binding disordered region, the binding profile is highly localized. In contrast, for a partner-binding structured protein, the binding profile comprises two (or more) localized regions that are considerably separated along the sequence. The separation results from bringing together different regions to form the active site in the structured protein. The DNA binding domain of p53 also has a complex, distinctive binding profile that is different from the profiles when binding to p53BP1 and p53BP2 [62]. The p53BP1 and p53BP2 profiles have similar p53 sequence localizations, but the detailed shapes of the profiles are quite distinctive.

Using structures currently in the PDB), five disordered sequences associated within a single binding groove in 14-3-3 provide an example of many-to-one signaling interactions. As suggested previously [3] the flexibility plays a major role enabling different sequences to fit into one binding site. Both backbone and side-chain flexibilities are needed to accomplish the structural shifts needed for the different sequences to fit into the common binding site [62].

Our earlier publication failed to consider the flexibility on the structured side of the complex (e.g. the flexibility in 14-3-3) for many-to-one signaling interactions. In this example, the structured protein side of the complex also uses flexibility to accommodate the binding of the many disordered segments to a common binding site.

The now famous induced-fit hypothesis was first proposed in 1958 [138]. In Koshland's original publication, a thought-experiment involving different amino acid side chains binding to a common site was described. For the different sequences to bind, an "induced fit" was suggested to be required in order to accommodate the different structures of the different side chains. The current textbook examples of induced fit describe an entirely different type of binding in which fairly rigid domains shift upon binding to their ligand. However, 14-3-3 binding to multiple peptides of different sequences is evidently the first example that closely corresponds to Koshland's original induced fit hypothesis. Comparing the interactions of 143-3 with the different peptide sequences confirms Koshland's original induced fit hypothesis, and these comparisons provide insight regarding the degree of structural change upon binding (manuscript in preparation).

\section{Intrinsic disorder and alternative splicing}

Two or more mature mRNAs are produced from a single precursor pre-mRNA by the inclusion and omission of different segments in a process called "alternative splicing" $[139,140]$. The "exons" are joined to form the mRNA and the "introns" are left out [141]. So far alternative splicing has been commonly observed only in multicellular eukaryotes [142]. For humans and other mammals, 40 $60 \%$ the genes yield proteins via the alternative splicing mechanism [143-145], and multiple proteins are often produced from a single gene. Alternative splicing very likely provides an important mechanism for enhancing protein diversity in multicellular eukaryotes [146]. 


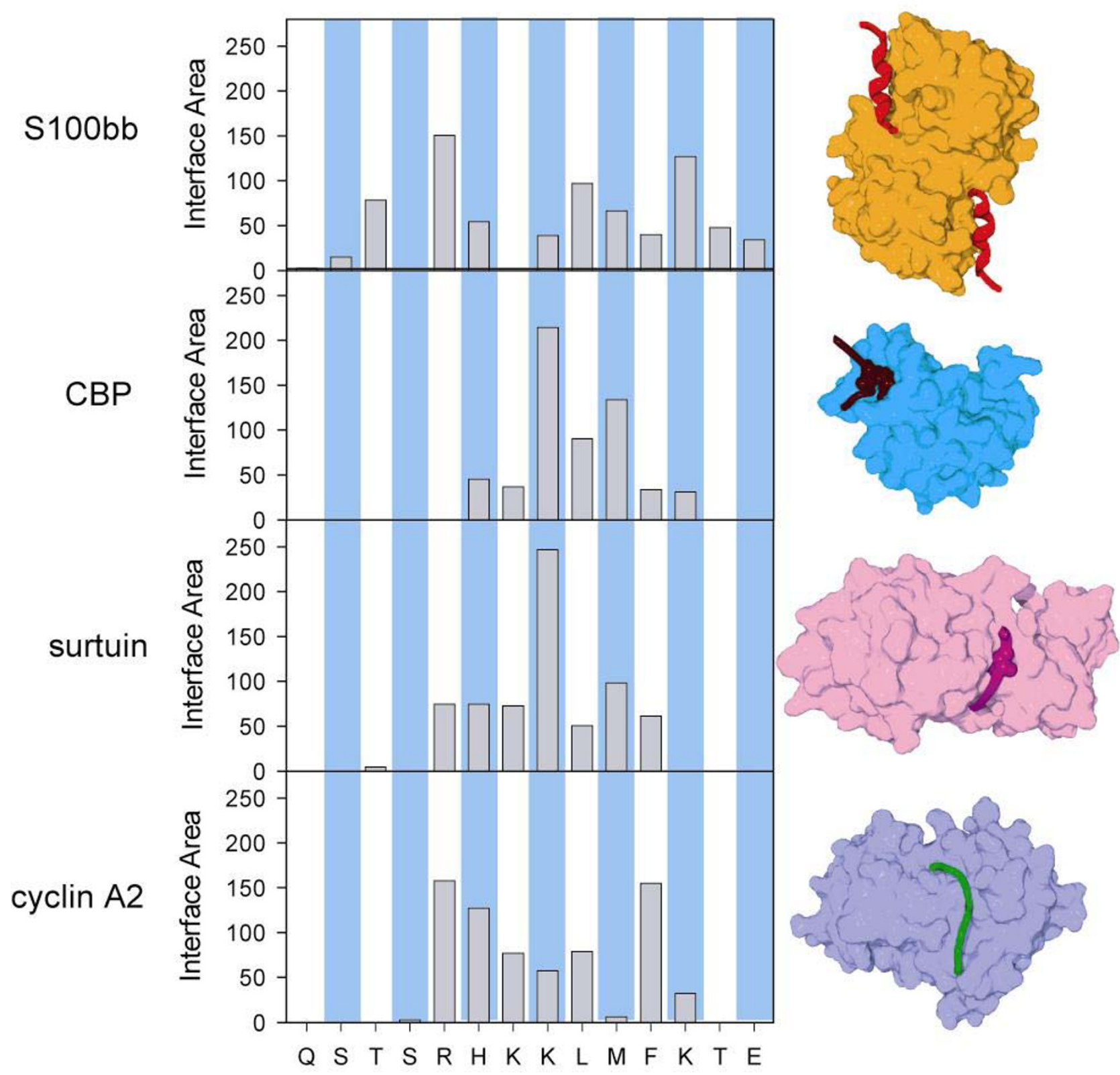

Figure 7

Sequence and structure comparison for the four overlapping complexes in the C-terminus of p53. (A) Primary, secondary, and quaternary structure of $\mathrm{p} 53$ complexes. (B) The $\triangle$ ASA for rigid association between the components of complexes for each residue in the relevant sequence region of $\mathrm{p} 53$. The two hatched bars indicate acetylated lysine residues. Histogram of conserved predicted disorder effective length classes by kingdom.

Alternative splicing has affects on a diversity of protein functions such as protein-protein interactions, ligand binding, and enzymatic activity [147-149]. Therefore it comes as no surprise that abnormal alternative splicing has been associated with numerous human diseases, examples being myotonic dystrophy [150], Axoospermia [151], Alzheimer's [152] and cancer [153].

Alternative splicing that maps to protein structure would often lead to dysfunctional protein folding, most often 
causing loss of function. In some cases, however, the alternatively spliced structured protein can maintain function, albeit typically with a reduction in activity.

For alternative splicing that maps to structure, the alterations are generally of small size, are usually located on the protein surface, and are most often located in coil regions [154]. These features support efforts to predict the affects of alternative splicing on protein structure (and function) by homology modeling [155] and by a more sophisticated structural modeling and analysis [154]. Given the small sizes and locations of the changes resulting from alternative splicing, the different splice variants were predicted to fold into the same overall structures, with only slight structural perturbations that could be functionally important.

The structural implications given above are interesting, but only a small fraction of alternative splicing events have been mapped to structured proteins. Given that $40 \%$ to $60 \%$ of mammalian (human) genes are estimated to undergo alternative splicing, and given that there are several thousand mammalian proteins in PDB [156], we would expect to find several thousand examples to study. So far, however, despite exhaustive searches of PDB, only 20 examples have been reported [154]. Given the failure to find a significant number of examples of alternative splicing that map to regions of structure, what is the alternative?

To further understand the relationship between alternative splicing and structure we searched for alternatively spliced isozyme pairs and were able to find just five such pairs with structures determined for both partners [157161]. Consistent with the modeling paper results discussed above [154], the folding of the protein isoforms pairs was nearly identical. The lack of significant structural perturbations occurred because alternatively spliced segments were either short regions on the surface of the structure (for two pairs) or were disordered regions (for the remaining three pairs). With regard to the two spliced structured segments, the larger structural perturbation corresponded to the omission of a short helix in the shorter splice variant. This omission led to a slight rearrangement of the neighboring secondary structure elements adjusted to accommodate the lack of the very short intervening helix. As for the three pairs for which the alternative splicing mapped to disordered regions, this suggests a possible explanation for the missing examples of splicing that map to the structures in the PDB.

Given the above data, we hypothesized that the protein folding problems discussed above would be solved for different isoforms if the alternatively spliced regions of mRNA were to code for regions of intrinsically disordered protein. If alternative splicing were to map to disordered regions, both multiple and long splice variants would be allowed because structural perturbation would not be a problem.

To test whether alternative splicing is associated with disorder, we built a collection of human proteins with structurally characterized regions of both structure and disorder. Next, we searched for data on alternative splicing for all of these proteins. At that time we were able to find just 46 human proteins with 75 alternatively spliced segments all of which were located in structurally characterized regions [64].

Figure 8 shows that of these 75 alternatively spliced regions of RNA, 43 (57\%) coded for entirely disordered protein, 18 (24\%) coded for both ordered and disordered protein (with the splice boundaries very often in, or very near to, the disordered regions), and just 14 (19\%) coded for fully structured regions [64].

While small in number, these 43 disorder-associated alternatively spliced regions and 18 mixed-structure regions are significantly larger than the 14 regions associated with regions of structure. Nevertheless, it would be very useful to enlarge the dataset.

To increase the number of examples, we identified all of the proteins in SwissProt labeled as having alternatively spliced isoforms, giving 558 proteins with 1,266 regions that are absent from one isoform due to alternative splic-

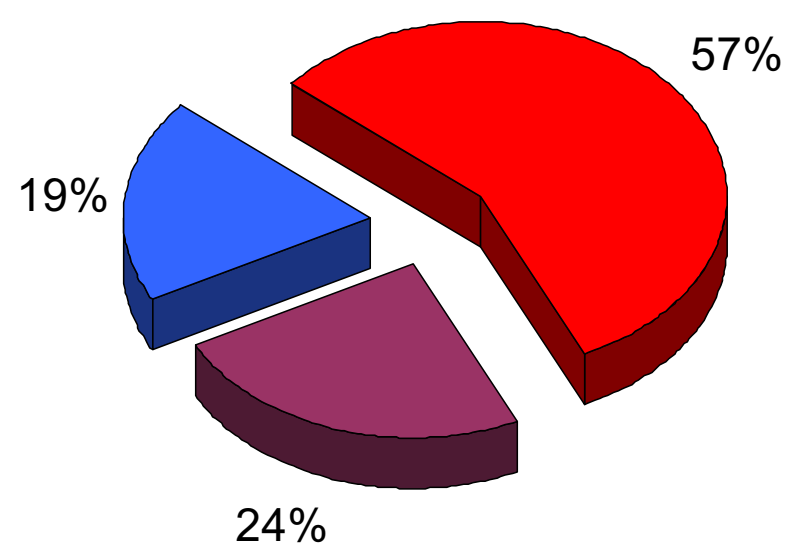

Figure 8

Abundance of intrinsic disorder in alternatively spliced regions. Fractions of alternatively spliced regions of RNA coded for entirely disordered protein, for both ordered and disordered protein, and for fully structured regions are shown as red, violet and blue pieces of the pie chart respectively. 
ing. Next, we predicted disorder/order for these alternatively spliced proteins and regions. As a control, we also predicted disorder/order for the 46 structurally characterized proteins and for their 75 regions that are affected by alternative splicing. For both datasets, we plotted the frequency of observation versus per cent disorder, with the disorder binned at the $20 \%$ level. The 75 alternatively spliced regions of known structure gave almost perfect agreement between predictions and observations. For the 1,266 regions from SwissProt, the predicted disorder closely matched the corresponding predictions for the 75 with known structure. These data strongly suggest that alternative splicing occurs mostly in regions of RNA that code for disordered protein.

Our previous predictions estimated that about $50 \%$ of mammalian proteins have disordered regions of 30 residues or longer [94]. These prediction results are similar to the estimate of $40 \%$ to $60 \%$ of mammalian genes that undergo alternative splicing. Thus, the overall likely frequency of intrinsic disorder is certainly high enough for $80 \%$ of alternative splicing events to occur in such regions.

In several sections given above, the various roles of disorder in protein functions and in protein-protein interaction networks are discussed. Modification of such functions including protein-protein interaction networks could be readily accomplished by alternative splicing within disordered regions. Thus, a linkage between alternative splicing and signaling by disordered regions provides a novel and plausible mechanism for understanding the origins of cell differentiation, which ultimately gave rise to multicellular organisms in nature [64]. New studies are needed to test these ideas.

\section{Conservation of intrinsic disorder in protein domains and families}

Many proteins possess complex domain structure. In fact, $\sim 65 \%$ proteins in unicellular organisms and $>80 \%$ proteins in metazoa, are multidomain proteins [162]. Traditionally, a domain is considered to be an independent (or semi-independent) part of a protein molecule that could fold autonomously, i.e., separately from the rest of the protein chain. Structural domains vary in length from between about 25 amino acids up to 500 amino acids in length. For structured proteins, domains have been described as units of independent folding [163], of compact structure [164] or of function and evolution [165]. Obviously, these definitions, being valid individually, may overlap and a conserved, compact structural domain is likely to be able to fold autonomously. Combinatorial usage of various structural and functional units creates a vast number of multidomain and multifunctional proteins [166], in which each domain may fulfill its own function independently, or in a concerted manner with its neighbors.

Recently $[65,66]$, to identify the prevalence, characteristics, and functions of conserved disordered regions within protein domains and families, a database was created that stores the amino acid sequences of nearly one million proteins and their domain matches from the InterPro database [167]. InterPro is a computational resource integrating several protein family and domain databases, including PRINTS, PROSITE, Pfam, ProDom, SMART and TIGRFAMs [167]. These million proteins were analyzed using PONDR ${ }^{\circledast}$ VL-XT disorder predictor and regions of sequence corresponding to domains were aligned using a multiple sequence alignment tool. Combining disorder prediction and conservation data, many regions of conserved predicted disorder were found within protein domains. This analysis identified 3653 regions of conserved disorder prediction, found within 2898 distinct InterPro entries [65]. Importantly, regions of conserved disorder prediction were found in protein domains from all available InterPro member databases. Furthermore, they were found in all kingdoms of life, including viruses [65]. Figure 9 emphasizes this fact and shows also that the majority of regions of conserved predicted disorder were short, with less than $10 \%$ of these regions founnd to exceed 30 residues in length. Most of the long conserved disordered regions were in domains from eukaryotic or viral proteins [65]. This is in line with our previous work, which found that long regions of intrinsic disorder were much more prevalent in eukaryotes than in prokaryotes $[30,48,168]$. This work has also shown that in addition to well-known conserved structural domains, protein domains and families have regions of conserved disorder. Most conserved disordered regions had sequence conservation greater than or equal to that in conserved ordered regions within the same protein. This indicated that disorder tendencies were kept in these proteins, suggesting that important functions likely depend on the disordered regions [65].

These regions of predicted disorder were found to be conserved within a large number of protein families and domains. Although many think of such conserved domains as being structured, in fact a significant number of them contain regions of disorder that are likely to be crucial to their functions [65]. The next crucial question was: What are the purposes of the regions of conserved predicted disorder? To answer this question, a functional repertoire of these regions was analyzed and a variety of functions were found to be associated with domains containing conserved disorder [66]. The most common were DNA/RNA binding and protein binding. Many ribosomal proteins also were found to contain conserved disordered regions. Other functions identified included membrane 


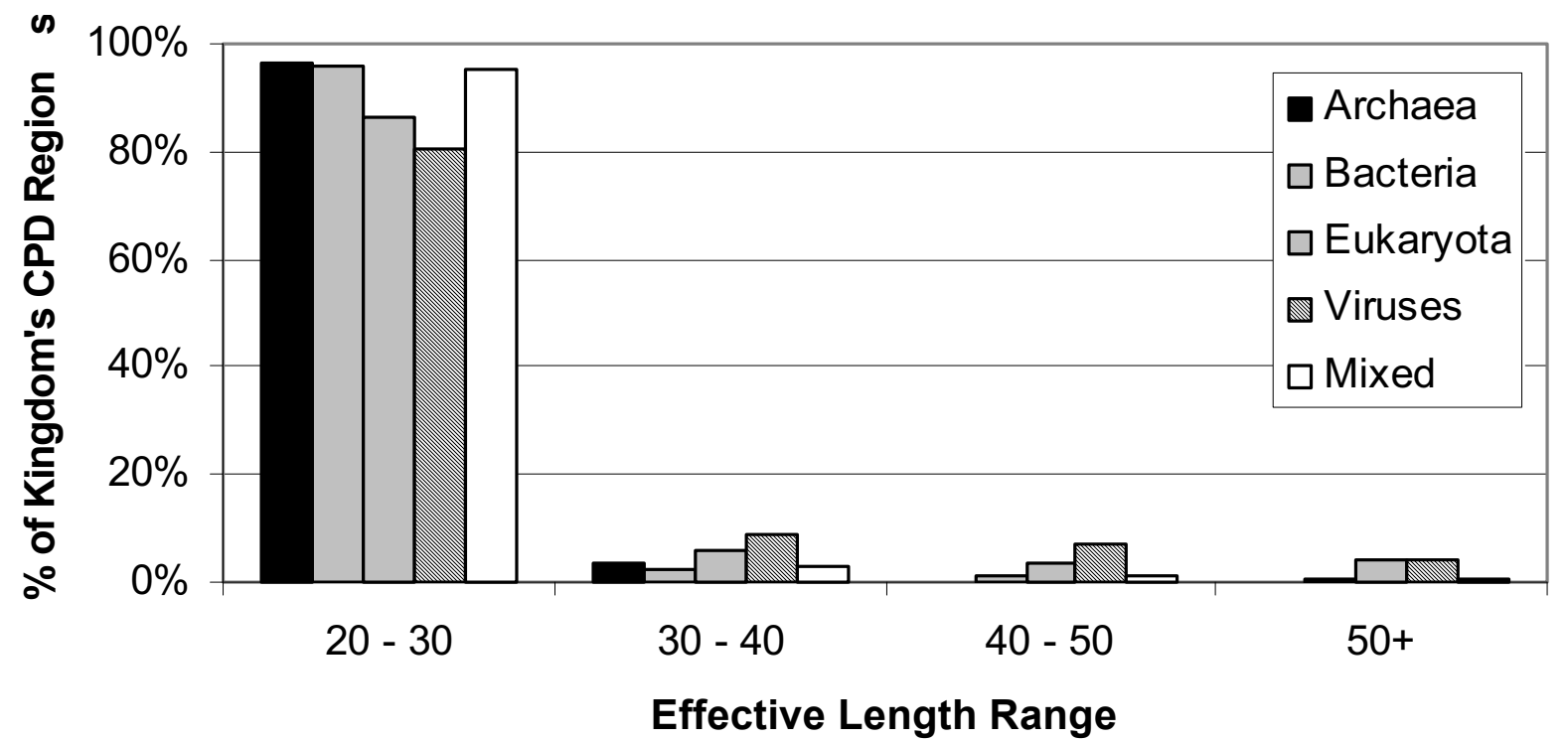

Figure 9

Abundance of conserved predicted disordered regions in various organisms. Histogram of conserved predicted disorder effective length classes by kingdom.

translocation and amino acid storage for germination. Due to limitations of both current knowledge and the methodology implemented in that study, it was not determined whether these functions were directly associated with the predicted disordered region [66]. Because in most cases the region of conserved predicted disorder covered only a part of the domain, it is possible that the disordered region is not required for the known function of the domain. However, given that this disorder is conserved through nearly all members of the domain, it seems likely that the disorder plays a role in at least one important function of the domain, whether that function is known or unknown. Furthermore, the functions associated with conserved disorder were in agreement with the functions found in other studies to correlate to disordered regions. We have established that intrinsic disorder may be more common in bacterial and archaeal proteins than previously thought, but this disorder is likely to be used for different purposes than in eukaryotic proteins, as well as occurring in shorter stretches of protein [66].

\section{The $D^{2}$ concept: abundance of untrinsic disorder in disease-related proteins}

Proteins are crucial for life, so it is not surprising that their dysfunction can cause pathological conditions. Indeed, a significant number of diseases arise from the failure of a specific peptide or protein to adopt its proper structure. Such diseases are associated with protein misfolding. Observed consequences of misfolding include protein aggregation (and/or fibril formation), loss of normal function, and gain of toxic function. Some proteins exhibit a marked tendency to assume a pathologic conformation, and this tendency becomes increasingly evident with aging or at persistently high concentrations caused by some condition. Sometimes endogenous factors, including for example chaperones, intracellular or extracellular matrixes, other proteins and small molecules, can alter the conformation of a pathogenic protein and thereby increase its propensity to misfold. Other causes of misfolding and misfunction include point mutation(s), exposure to internal or external toxins, impaired posttranslational modifications (phosphorylation, advanced glycation, deamidation, racemization, acetylation, etc.), an increased probability of degradation, impaired trafficking, loss of binding partners or oxidative damage. These various factors can act independently or in complex associations. Intrinsically disordered proteins known as "hubs" associate with large numbers of partners (see above). Furthermore, such proteins often exhibit significant structural variability, forming different monomeric, oligomeric and insoluble conformations depending on the environment and suggesting that some of these proteins fold in a template-dependent manner (e.g., see [68]). From these observations, we proposed that the development of conformational diseases may originate, not only from misfolding, but also from misidentification, misregulation and missignaling [73]. That is, mutations and/or changes in the environment could cause 
protein confusion, thereby reducing the ability to recognize appropriate binding partners and leading instead to the occurrence of deadly aggregates.

Data scattered in literature for individual proteins unambiguously show that some proteins involved in human diseases such as cancer, Parkinson's disease and other synucleinopathies, Alzheimer's, prion diseases, diabetes, and cardiovascular disease are either completely disordered or contain long disordered regions. This immediately raises the question of how abundant are such proteins in various pathological conditions. To answer this question, several sets of proteins related to various diseases, including cancer and cardiovascular disease (CVD), were collected and analyzed using a number of disorder predictors $[67,70,71]$. Results of these analyses are systemized in Figure 10, which shows percentages of proteins with $\geq 30$ consecutive residues predicted to be disordered in datasets of proteins associated with cancer, CVD, neurodegenerative disease and diabetes [73]. This illustrates that intrinsic disorder is highly prevalent in CVD-, diabetes-, cancer, and neurodegenerative diseaserelated proteins, being comparable with that of signaling proteins and significantly exceeds the level of intrinsic disorder in eukaryotic proteins from SWISS-PROT and in non-homologous, structured proteins from the PDB. In fact, $79 \%$ of cancer-associated and $61 \%$ of CVD-associ-

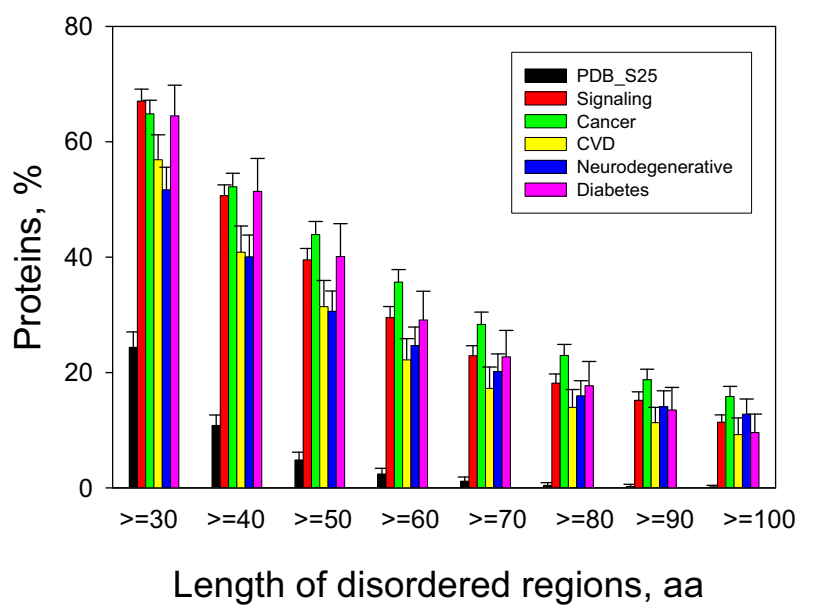

\section{Figure 10}

Abundance of intrinsic disorder in disease-associated proteins. Percentages of disease associated proteins with $\geq$ 30 to $\geq 100$ consecutive residues predicted to be disordered. The error bars represent $95 \%$ confidence intervals and were calculated using I,000 bootstrap re-sampling. Corresponding data for signaling and ordered proteins are shown for the comparison. Analyzed sets of disease-related proteins included 1786, 487, 689, and 285 proteins for cancer, CVD, neurodegenerative disease and diabetes, respectively. ated proteins were found to contain predicted regions of disorder of 30 residues or longer $[67,70,71,73]$.

Using CVD as an illustrative example, the hypothesis that high level of intrinsic disorder could be important for function of disease-related proteins, and for the control and regulation of processes associated with cardiovascular disease was confirmed by finding that $198 \alpha$-MoRFs were predicted in 101 proteins from the CVD dataset [71]. The mentioned number of MoRFs is important because these features provide the starting point for disorder-based drug discovery (see below). A comparison of disorder predictions with the experimental structural and functional data for a subset of the CVD-associated proteins indicated good agreement between predictions and observations.

Additional confirmation of the high prevalence of intrinsically disordered proteins in human diseases came from the described above functional annotation over the entire Swiss Protein database from a structured-versus-disordered point of view [55-57]. In fact, this analysis revealed that many diseases are strongly correlated with proteins predicted to be disordered. Contrary to this, we did not find disease-associated proteins to be strongly correlated with absence of disorder [57]. Among disease-related Swiss-Prot keywords strongly associated with intrinsic disorder were oncoproteins, malaria, trypanosomiasis, human immunodeficiency virus (HIV) and acquired immunodeficiency syndrome (AIDS), deafness, obesity, cardiovascular disease, diabetes mellitus, albinism, and prion [57]. Thus, intrinsic disorder is very common in disease-associated proteins, giving rise to the disorder in disorders concept, which we are calling the " $\mathrm{D}^{2}$ concept." [73].

This high abundance of intrinsic disorder in proteins involved in various diseases suggests that they possess a number of specific features that make them key players in the development of pathological conditions. Intrinsically disordered regions or entire proteins are among major cellular regulators, recognizers and signal transducers. Their functionality is modulated via a number of posttranslational modifications and also can be tuned and made organ/tissue specific via the alternative splicing of corresponding mRNAs. Many intrinsically disordered regions and intrinsically disordered proteins can fold (completely or partially) upon interaction with corresponding binding partners, ensuring low-affinity/high-specificity binding. They possess multiple binding specificity and they are able to participate in one-to-many and many-to-one interactions [73]. All this makes intrinsically disordered regions and intrinsically disordered proteins very attractive targets for the development of a novel class of drugs aiming modulation of protein-protein interactions. 


\section{Intrinsic disorder and drug discovery}

For a long time protein-protein interactions have been a potential source of drug targets. Indeed, determining the protein interactome by systems biology approaches and understanding of these results at a deeper level points to interesting drug targets [169]. Despite such interest, developing drug molecules that block protein-protein interactions has not yet been successful $[170,171]$. Indeed, our searches of the current literature have failed to yield even one currently used drug molecule that functions by inhibiting a protein-protein interactions.

Even though there has been little success in finding drugs that act by blocking protein-protein interactions, several promising molecules are encouraging a renewed interest in this approach [172-175]. As pointed out in these recent discussions, several interesting drug-like lead compounds apparently function by blocking protein-protein interactions, and these leads are being actively pursued via drugdiscovery strategies.

One very important interaction of interest, specifically the p53/Mdm2 interaction, has been the focus of multiple drug-discovery studies [176-178]. We became interested in this example because the binding region of p53 is intrinsically disordered [179]. However, the papers that discuss this interaction as a promising drug target don't even mention the disorder-to-order transition for the p53 partner.

Bioinformatics and computational structural biology tools were employed to investigate this interaction, and these studies revealed several features that explained why this region is so promising as a drug target. Next, we searched for similar features in other proteins contained in the human proteome. By this approach we found thousands of possible new drug targets involving one disordered partner. Many examples of these new targets are found for each of the major diseases [75]. Clearly a great deal of work is needed to find actual drug molecules based on these bioinformatics studies, but in our view these new leads merit systematic study.

A protein-protein interaction involving one disordered partner and one structured partner has several features that are consistent with being a good target for drug discovery. First, unlike most interfaces between two structured proteins, the interface between one structured and one disordered partner is almost never flat. Usually the structured partner has a cleft in the interface, while the disordered region typically becomes organized into a helix or other structure with hydrophobic side chains that project away from the backbone and into the cleft. Such features occur over and over in our MoRF dataset [59] and also in the examples used to develop the MoRF predictors
$[58,61]$. With respect to the p53/Mdm2 interaction, the p53 binding site is predicted to be an $\alpha-M o R F$, and this binding site contains hydrophobic side chains that project deeply into the cleft located on the surface of the Mdm2 partner.

For these disorder-based interactions, the disordered partner "morphs" from disorder-to-order, and, therefore, some of the binding energy must be spent to overcome the higher entropy of the unfolded state. Such an interaction is therefore likely to be weaker than a similar-sized interaction between two structured proteins. This entropy penalty means that such interactions will likely be easier to block with a small molecule competitor as compared to a similar interaction between two structured proteins.

Protein disorder is not discussed or even mentioned in any of the papers touting protein-protein interactions as new targets for drug discovery. Nevertheless, 4 of the 8 examples described in these recent reviews [172,174] depend on one structured partner and one disordered partner. Furthermore, in 3 of the 4 examples, the disordered segments, or at least part of the disordered segment morphs into a helix upon binding (see Figure 11). Thus, the $\mathrm{p} 53 / \mathrm{Mdm} 2$ complex is not alone in being a disorderbased interaction that is blocked by a small drug-like molecule. Many more examples are likely to appear in the coming years, and we anticipate that some of these examples will eventually lead to new drug molecules.

\section{Conclusion}

The concepts regarding drug discovery can be linked with the concepts regarding alternative splicing. Together, these two concepts suggest approaches that could lead to the development of tissue-specific drugs via taking into account tissue-specific alternative splicing in disordered regions that form protein-protein interactions that can be blocked by small molecules. Such tissue-specific drug molecules might have fewer side effects than current drug molecules.

The concepts regarding drug discovery can be linked with the concepts regarding protein-protein interactions. Together these two concepts suggest two distinct possibilities. First is the possibility of one drug molecule blocking one protein-protein interaction (for one-to-many signaling interactions). Second is the possibility of one drug molecule blocking many interactions (for many-to-one signaling interactions). Experiments could be designed to focus specifically on these distinct classes of interactions to determine possible differential biological effects of these two distinct possibilities.

The concepts of drug discovery can be linked with the concepts regarding the functions of intrinsically disordered 


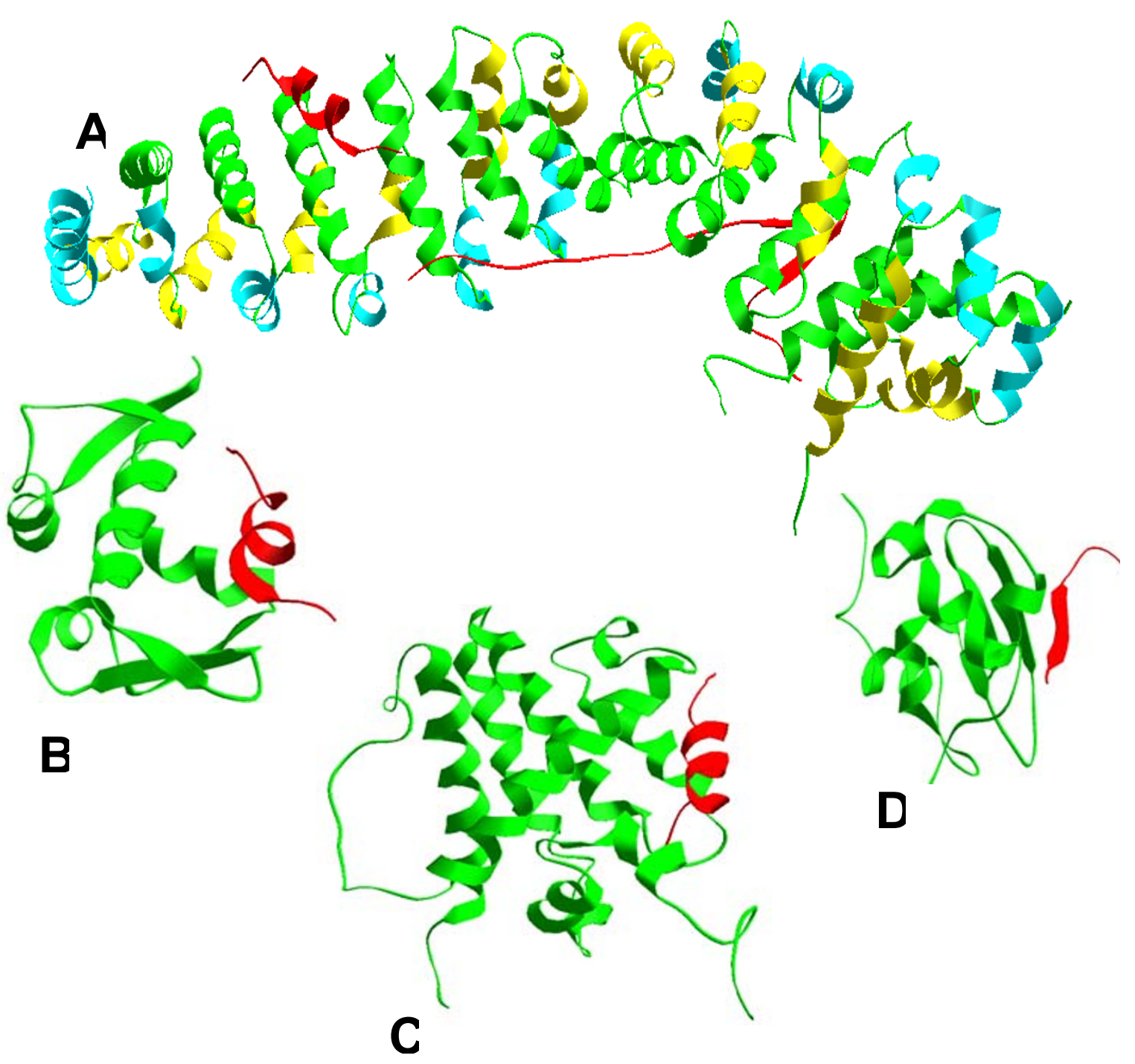

\section{Figure II}

IDPs as drug targets. Protein-protein interactions involving $\alpha$-helical or $\beta$-strand portion of the partners are used to design small molecules for cancer drugs. A. A ribbon diagram of complex of $\beta$-catenin (light colors) and T cell factor (red) was regenerated from PDB IG3]. The structure of $\beta$-catenin is consisted of 12 tri-helical repeats (except the repeat 7 , which just has two helical units). Small molecules from a natural-product library were screened and a couple of inhibitors were found. However, the binding sites for the small molecule inhibitors were not clear. B. A ribbon diagram of complex of MDM2 (green) and P53 fragment (red) was regenerated from PDB IYCR. Small molecule inhibitors were designed based on the structure of the helical fragment of P53. C. A ribbon diagram of complex of Bcl-xL (green) and BAK fragment (red) was regenerated from PDB IBXL. Small molecules were designed based on the 20-residue helix of BAK to inhibit the interaction. D. A ribbon diagram of complex of XIAP (green) and Smac fragment (red) was regenerated from PDB IG3F. Small molecule inhibitors were designed based on the $\beta$-strand fragment (AVPIAQKSE) of Smac.

regions. Together these concepts suggest new strategies for finding drugs aimed at a wide variety of signaling and regulatory functions.
We began to apply bioinformatics to the set of disordered proteins about 12 years ago, with our first paper being published slightly more than 10 years ago [86]. During this decade our understanding of the biological functions 
and importance of these proteins has undergone a significant improvement. Perhaps the next decade will pave the way for practical outcomes (such as new drug molecules) from the study of these proteins.

\section{Competing interests}

The authors declare that they have no competing interests.

\section{Authors' contributions}

$\mathrm{CJO}, \mathrm{VV}$, and JWC have done the computational analysis, designed figures and contributed to the manuscript writing. JM and JYY were involved in finding and analysis of p53 and 14-3-3 binding partners. VNU was involved in planning of experiments, contributed to the manuscript writing and revised the final version. AKD was involved in design and planning of all the experiments, drafted the manuscript and headed the project. All authors have read and approved the final manuscript.

\section{Acknowledgements}

This work was supported in part by the grants ROI LM007688-0IAI (to A.K.D and V.N.U.) and GM07I7I4-0IA2 (to A.K.D and V.N.U.) from the National Institutes of Health and the Programs of the Russian Academy of Sciences for the "Molecular and cellular biology" and "Fundamental science for medicine" (to V. N. U.). We gratefully acknowledge the support of the IUPUI Signature Centers Initiative.

This article has been published as part of

Volume 9 Supplement 2, 2008: IEEE 7th International Conference on Bioinformatics and Bioengineering at Harvard Medical School. The full contents of the supplement are available online at http://www.biomedcentral.com/I47/-2I64/ 9? issue $=\$ 2$

\section{References}

I. Landsteiner K: The specificity of serological reactions. Baltimore: C. C. Thomas; 1936.

2. Pauling L: A Theory of the Structure and Process of Formation of Antibodies. J Am Chem Soc 1940, 62( (10):2643-2657.

3. Dunker AK, Garner E, Guilliot S, Romero P, Albrecht K, Hart J, Obradovic Z, Kissinger C, Villafranca JE: Protein disorder and the evolution of molecular recognition: theory, predictions and observations. Pac Symp Biocomput 1998:473-484.

4. Karush F: Heterogeneity of the binding sites of bovine serum albumin. J Am Chem Soc 1950, 72:2705-27I3.

5. Spolar RS, Record MT Jr: Coupling of local folding to site-specific binding of proteins to DNA. Science 1994, 263(5 | 48): 777-784.

6. Pontius BW: Close encounters: why unstructured, polymeric domains can increase rates of specific macromolecular association. Trends Biochem Sci 1993, 18(5):181-186.

7. Shoemaker BA, Portman JJ, Wolynes PG: Speeding molecular recognition by using the folding funnel: the fly-casting mechanism. Proc Natl Acad Sci USA 2000, 97( 16):8868-8873.

8. Sugase K, Dyson HJ, Wright PE: Mechanism of coupled folding and binding of an intrinsically disordered protein. Nature 2007, 447(7 | 47): I02I-1025.

9. Galea CA, Nourse A, Wang Y, Sivakolundu SG, Heller WT, Kriwacki RW: Role of intrinsic flexibility in signal transduction mediated by the cell cycle regulator, p27 Kipl. J Mol Biol 2008, 376(3):827-838.

10. McMeekin TL: Milk proteins. Journal of Food Protection 1952, 15:57-63.

II. Halwer M: Light-scattering study of effect of electrolytes on alpha- and beta-casein solutions. Arch Biochem Biophys 1954, $5 \mathrm{I}(\mathrm{I}): 79-87$
12. Jirgensons B: Classification of proteins according to conformation. Die Makromolekulare Chemie 1966, 9 I(I):74-86.

13. Doolittle RF: Structural aspects of the fibrinogen to fibrin conversion. Adv Protein Chem 1973, 27:1-109.

14. Vucetic S, Obradovic Z, Vacic V, Radivojac P, Peng K, lakoucheva LM, Cortese MS, Lawson JD, Brown CJ, Sikes JG, et al.: DisProt: a database of protein disorder. Bioinformatics (Oxford, England) 2005, 2I(1):137-140.

15. Sickmeier M, Hamilton JA, LeGall T, Vacic V, Cortese MS, Tantos A, Szabo B, Tompa P, Chen J, Uversky VN, et al.: DisProt: the Database of Disordered Proteins. Nucleic acids research 2007:D786-793.

16. Morar AS, Olteanu A, Young GB, Pielak GJ: Solvent-induced collapse of alpha-synuclein and acid-denatured cytochrome $c$. Protein Sci 200 I, I O(I I):2195-2199.

17. Flaugh SL, Lumb KJ: Effects of macromolecular crowding on the intrinsically disordered proteins c-Fos and p27(Kip I). Biomacromolecules 200I, 2(2):538-540.

18. Dedmon MM, Patel CN, Young GB, Pielak GJ: FlgM gains structure in living cells. Proc Natl Acad Sci USA 2002, 99(20): | $268|-| 2684$.

19. McNulty BC, Young GB, Pielak GJ: Macromolecular crowding in the Escherichia coli periplasm maintains alpha-synuclein disorder. J Mol Biol 2006, 355(5):893-897.

20. Selenko P, Wagner G: Looking into live cells with in-cell NMR spectroscopy. J Struct Biol 2007, I 58(2):244-253.

21. Bryant JE, Lecomte JT, Lee AL, Young GB, Pielak Gl: Protein dynamics in living cells. Biochemistry 2005, 44(26):9275-9279.

22. Bryant JE, Lecomte JT, Lee AL, Young GB, Pielak GJ: Retraction. Protein dynamics in living cells. Biochemistry 2007, 46(27):8206.

23. Holt C, Sawyer L: Caseins as rheomorphic proteins: interpretation of primary and secondary structures of the $\alpha$ sI-, $\beta$-, and K-caseins. J Chem Soc Faraday Trans 1993, 89:2683-2692.

24. Schweers O, Schonbrunn-Hanebeck E, Marx A, Mandelkow E: Structural studies of tau protein and Alzheimer paired helical filaments show no evidence for beta-structure. J Biol Chem 1994 , 269(39):24290-24297.

25. Weinreb PH, Zhen W, Poon AW, Conway KA, Lansbury PT Jr: NACP, a protein implicated in Alzheimer's disease and learning, is natively unfolded. Biochemistry 1996, 35(43): 13709-137|5.

26. Wright PE, Dyson HJ: Intrinsically unstructured proteins: reassessing the protein structure-function paradigm. Journal of molecular biology 1999, 293(2):32I-331.

27. Romero P, Obradovic Z, Kissinger C, Villafranca JE, Dunker AK: Identifying disordered regions in proteins from amino acid sequence. Proceedings of the IEEE International Conference on Neural Networks 1997, I:90-95.

28. Daughdrill GW, Pielak G], Uversky VN, Cortese MS, Dunker AK Natively Disordered Proteins. In Protein Folding Handbook, Part II Edited by: Buchner J, Kiefhaber T. Weinheim: Wiley-VCH; 2005:275-357.

29. Dunker AK: Disordered proteins. In Encyclopedia of Life Sciences John Wiley \& Sons in press.

30. Dunker AK, Lawson JD, Brown CJ, Williams RM, Romero P, Oh JS, Oldfield CJ, Campen AM, Ratliff CM, Hipps KW, et al:: Intrinsically disordered protein. Journal of molecular graphics \& modelling $200 \mathrm{I}$, 19(I):26-59.

31. Uversky VN: Natively unfolded proteins: a point where biology waits for physics. Protein Sci 2002, I I (4):739-756.

32. Uversky VN, Oldfield C], Dunker AK: Showing your ID: intrinsic disorder as an ID for recognition, regulation and cell signaling. J Mol Recognit 2005, I 8(5):343-384.

33. Dyson HJ, Wright PE: Intrinsically unstructured proteins and their functions. Nature reviews 2005, 6(3): 197-208.

34. Bracken C, lakoucheva LM, Romero PR, Dunker AK: Combining prediction, computation and experiment for the characterization of protein disorder. Curr Opin Struct Biol 2004, |4(5):570-576.

35. Crick SL, Jayaraman M, Frieden C, Wetzel R, Pappu RV: Fluorescence correlation spectroscopy shows that monomeric polyglutamine molecules form collapsed structures in aqueous solutions. Proc Natl Acad Sci USA 2006, 103(45):16764-16769.

36. Vitalis A, Wang X, Pappu RV: Quantitative characterization of intrinsic disorder in polyglutamine: insights from analysis based on polymer theories. Biophys J 2007, 93(6): 1923-1937. 
37. Uversky VN, Gillespie JR, Fink AL: Why are "natively unfolded" proteins unstructured under physiologic conditions? Proteins 2000, 4 I (3):4I5-427.

38. Uversky VN: Natively unfolded proteins: a point where biology waits for physics. Protein Sci 2002, I I (4):739-756.

39. Uversky VN: What does it mean to be natively unfolded? Eur Biochem 2002, 269(I):2-12.

40. Radivojac P, lakoucheva LM, Oldfield CJ, Obradovic Z, Uversky VN, Dunker AK: Intrinsic disorder and functional proteomics. Biophys J 2007, 92(5): |439-|456.

41. Williams RM, Obradovi Z, Mathura V, Braun W, Garner EC, Young J, Takayama S, Brown CJ, Dunker AK: The protein non-folding problem: amino acid determinants of intrinsic order and disorder. Pac Symp Biocomput 2001:89-100.

42. Campen A, Williams RM, Brown C], Uversky VN, Dunker AK: TOP. IDP-Scale: A new amino acid scale measuring propensity for intrinsic disorder. Protein and Peptide Letters 2008 in press.

43. Vucetic S, Obradovic Z, Vacic V, Radivojac P, Peng K, lakoucheva LM, Cortese MS, Lawson JD, Brown CJ, Sikes JG, et al.: DisProt: a database of protein disorder. Bioinformatics 2005, 2 I (I): | 37-| 40.

44. Vacic V, Uversky VN, Dunker AK, Lonardi S: Composition Profiler: a tool for discovery and visualization of amino acid composition differences. BMC Bioinformatics 2007, 8:2I I.

45. Melamud E, Moult J: Evaluation of disorder predictions in CASP5. Proteins 2003, 53(Suppl 6):561-565.

46. Jin $Y$, Dunbrack RL Jr: Assessment of disorder predictions in CASP6. Proteins 2005, 6 I (Suppl 7): 167-175.

47. Bordoli L, Kiefer F, Schwede T: Assessment of disorder predictions in CASP7. Proteins 2007, 69(Suppl 8): I29-136.

48. Oldfield CJ, Cheng Y, Cortese MS, Brown CJ, Uversky VN, Dunker $\mathrm{AK}$ : Comparing and combining predictors of mostly disordered proteins. Biochemistry 2005, 44(6): | 989-2000.

49. Peng K, Vucetic S, Radivojac P, Brown C], Dunker AK, Obradovic Z: Optimizing long intrinsic disorder predictors with protein evolutionary information. J Bioinform Comput Biol 2005 , 3(I):35-60.

50. Peng K, Radivojac P, Vucetic S, Dunker AK, Obradovic Z: Lengthdependent prediction of protein intrinsic disorder. BMC Bioinformatics 2006, 7:208.

5I. Ferron F, Longhi S, Canard B, Karlin D: A practical overview of protein disorder prediction methods. Proteins 2006, 65(I): I- |4

52. Dunker AK, Obradovic Z, Romero P, Garner EC, Brown C): Intrinsic protein disorder in complete genomes. Genome Inform Ser Workshop Genome Inform 2000, I I:I6I-I7I.

53. Ward J, Sodhi JS, McGuffin LJ, Buxton BF, Jones DT: Prediction and functional analysis of native disorder in proteins from the three kingdoms of life. Journal of molecular biology 2004 337(3):635-645.

54. Dunker AK, Obradovic Z: The protein trinity - linking function and disorder. Nature biotechnology 200I, I 9(9):805-806.

55. Xie H, Vucetic S, lakoucheva LM, Oldfield C], Dunker AK, Uversky VN, Obradovic Z: Functional anthology of intrinsic disorder. I. Biological processes and functions of proteins with long disordered regions. Journal of proteome research 2007, 6(5): $1882-1898$

56. Vucetic S, Xie H, lakoucheva LM, Oldfield C], Dunker AK, Obradovic Z, Uversky VN: Functional anthology of intrinsic disorder. 2. Cellular components, domains, technical terms, developmental processes, and coding sequence diversities correlated with long disordered regions. Journal of proteome research 2007, 6(5): 1899-1916.

57. Xie H, Vucetic S, lakoucheva LM, Oldfield CJ, Dunker AK, Obradovic Z, Uversky VN: Functional anthology of intrinsic disorder. 3. Ligands, post-translational modifications, and diseases associated with intrinsically disordered proteins. Journal of proteome research 2007, 6(5): 1917-1932.

58. Oldfield Cl, Cheng Y, Cortese MS, Romero P, Uversky VN, Dunker $A K$ : Coupled folding and binding with alpha-helix-forming molecular recognition elements. Biochemistry 2005 , 44(37): I 2454- I 2470.

59. Mohan A, Oldfield CJ, Radivojac P, Vacic V, Cortese MS, Dunker AK, Uversky VN: Analysis of molecular recognition features (MoRFs). I Mol Biol 2006, 362(5): I043-1059.

60. Vacic V, Oldfield CJ, Mohan A, Radivojac P, Cortese MS, Uversky VN, Dunker AK: Characterization of molecular recognition fea- tures, MoRFs, and their binding partners. J Proteome Res 2007, 6(6):235I-2366.

6I. Cheng Y, Oldfield CJ, Romero P, Uversky VN, Dunker AK: Mining $\alpha$-helix-forming molecular recognition features $\alpha$-MoRFs with cross species sequence alignments. Biochemistry 2007, 46(47): $13468-13477$

62. Oldfield CJ, Meng J, Yang JY, Uversky VN, Dunker AK: Intrinsic disorder in protein-protein interaction networks: Case studies of complexes involving p53 and 14-3-3. In The 2007 International Conference on Bioinformatics and Computational Biology: June 25-28, 2007; Las Vegas, Nevada, USA CSREA Press; 2007:553-564.

63. Oldfield CJ, Meng J, Yang JY, Yang MQ, Uversky VN, Dunker AK Flexible nets: Disorder and induced fit in the associations of p53 and 14-3-3 with their partners. BMC Genomics 2008, 9(SI):SI

64. Romero PR, Zaidi S, Fang YY, Uversky VN, Radivojac P, Oldfield CJ, Cortese MS, Sickmeier M, LeGall T, Obradovic Z, et al.: Alternative splicing in concert with protein intrinsic disorder enables increased functional diversity in multicellular organisms. Proceedings of the National Academy of Sciences of the United States of America 2006, 103(22):8390-8395.

65. Chen JW, Romero P, Uversky VN, Dunker AK: Conservation of intrinsic disorder in protein domains and families: I. A database of conserved predicted disordered regions. J Proteome Res 2006, 5(4):879-887.

66. Chen JW, Romero P, Uversky VN, Dunker AK: Conservation of intrinsic disorder in protein domains and families: II. functions of conserved disorder. J Proteome Res 2006, 5(4):888-898.

67. lakoucheva LM, Brown CJ, Lawson JD, Obradovic Z, Dunker AK Intrinsic disorder in cell-signaling and cancer-associated proteins. I Mol Biol 2002, 323(3):573-584.

68. Uversky VN: A protein-chameleon: conformational plasticity of alpha-synuclein, a disordered protein involved in neurodegenerative disorders. I Biomol Struct Dyn 2003, 2 I (2):2 I I-234

69. Uversky VN: Protein folding revisited. A polypeptide chain at the folding-misfolding-nonfolding cross-roads: which way to go? Cell Mol Life Sci 2003, 60(9): |852-|87|.

70. Uversky VN, Roman A, Oldfield CJ, Dunker AK: Protein intrinsic disorder and human papillomaviruses: increased amount of disorder in E6 and E7 oncoproteins from high risk HPVs. Proteome Res 2006, 5(8): |829-|842.

7I. Cheng Y, LeGall T, Oldfield C], Dunker AK, Uversky VN: Abundance of intrinsic disorder in protein associated with cardiovascular disease. Biochemistry 2006, 45(35): I0448-10460.

72. Uversky VN: Neuropathology, biochemistry, and biophysics of alpha-synuclein aggregation. J Neurochem 2007, I 03(I): I 7-37.

73. Uversky VN, Oldfield C], Dunker AK: Intrinsically disordered proteins in human diseases: Introducing the D2 concept. Ann Rev Biophys Mol Biol 2008, 37:2 I 5-246.

74. Uversky VN: Amyloidogenesis of natively unfolded proteins. Current Alzheimer Research 2008 in press.

75. Cheng Y, LeGall T, Oldfield CJ, Mueller JP, Van YY, Romero P, Cortese MS, Uversky VN, Dunker AK: Rational drug design via intrinsically disordered protein. Trends in biotechnology 2006, 24( 10$)$ :435-442.

76. Webster T, Tsai H, Kula M, Mackie GA, Schimmel P: Specific sequence homology and three-dimensional structure of an aminoacyl transfer RNA synthetase. Science (New York, NY) |984, 226(4680): | 3|5-|3|7.

77. Thornton JW, DeSalle R: Gene family evolution and homology: genomics meets phylogenetics. Annual review of genomics and human genetics 2000, I:41-73.

78. Friedberg I: Automated protein function prediction - the genomic challenge. Briefings in bioinformatics 2006, 7(3):225-242.

79. Ofran Y, Punta M, Schneider R, Rost B: Beyond annotation transfer by homology: novel protein-function prediction methods to assist drug discovery. Drug discovery today 2005, I O(2 I): |475- | 482

80. Bagley SC, Altman RB: Characterizing the microenvironment surrounding protein sites. Protein Sci 1995, 4(4):622-635.

81. Mooney SD, Liang MH, DeConde R, Altman RB: Structural characterization of proteins using residue environments. Proteins 2005, 6 I (4):74l-747.

82. Fetrow JS, Skolnick J: Method for prediction of protein function from sequence using the sequence-to-structure-to-function paradigm with application to glutaredoxins/thioredoxins and 
TI ribonucleases. Journal of molecular biology 1998 28 I(5):949-968

83. Lichtarge O, Bourne HR, Cohen FE: An evolutionary trace method defines binding surfaces common to protein families. Journal of molecular biology 1996, 257(2):342-358.

84. Lopez G, Valencia A, Tress ML: firestar - prediction of functionally important residues using structural templates and alignment reliability. Nucleic acids research 2007:W573-577.

85. Youn E, Peters B, Radivojac P, Mooney SD: Evaluation of features for catalytic residue prediction in novel folds. Protein Sci 2007 16(2):216-226.

86. Garner E, Cannon P, Romero P, Obradovic Z, Dunker AK: Predicting Disordered Regions from Amino Acid Sequence: Common Themes Despite Differing Structural Characterization. Genome Inform Ser Workshop Genome Inform 1998, 9:201-213.

87. Dunker AK, Brown CJ, Lawson JD, lakoucheva LM, Obradovic Z: Intrinsic disorder and protein function. Biochemistry 2002, 4I(2I):6573-6582.

88. Dunker AK, Brown CJ, Obradovic Z: Identification and functions of usefully disordered proteins. Advances in protein chemistry 2002, 62:25-49.

89. Greene LH, Lewis TE, Addou S, Cuff A, Dallman T, Dibley M, Redfern $O$, Pearl F, Nambudiry R, Reid A, et al.: The CATH domain structure database: new protocols and classification levels give a more comprehensive resource for exploring evolution. Nucleic acids research 2007:D291-297.

90. Andreeva A, Howorth D, Brenner SE, Hubbard TJ, Chothia C, Murzin AG: SCOP database in 2004: refinements integrate structure and sequence family data. Nucleic acids research 2004:D226-229.

91. Holm L, Ouzounis C, Sander C, Tuparev G, Vriend G: A database of protein structure families with common folding motifs. Protein Sci 1992, I( I 2): 169|-1698.

92. Vucetic S, Brown CJ, Dunker AK, Obradovic Z: Flavors of protein disorder. Proteins 2003, 52(4):573-584.

93. Lobley A, Swindells MB, Orengo CA, Jones DT: Inferring function using patterns of native disorder in proteins. PLOS Comput Bio 2007, 3(8): el 62

94. lakoucheva LM, Brown CJ, Lawson JD, Obradovic Z, Dunker AK: Intrinsic disorder in cell-signaling and cancer-associated proteins. Journal of molecular biology 2002, 323(3):573-584.

95. MacBeath G, Kast P, Hilvert D: Redesigning enzyme topology by directed evolution. Science (New York, NY) 1998 279(5358): $|958-196|$.

96. Garner E, Romero P, Dunker AK, Brown C, Obradovic Z: Predicting Binding Regions within Disordered Proteins. Genome Inform Ser Workshop Genome Inform 1999, 10:4I-50.

97. Aasland R, Abrams C, Ampe C, Ball LJ, Bedford MT, Cesareni G, Gimona M, Hurley JH, Jarchau T, Lehto VP, et al.: Normalization of nomenclature for peptide motifs as ligands of modular protein domains. FEBS letters 2002, 5 I 3(I): $14|-| 44$.

98. Puntervoll P, Linding R, Gemund C, Chabanis-Davidson S, Mattingsdal M, Cameron S, Martin DM, Ausiello G, Brannetti B, Costantini A, et al.: ELM server: A new resource for investigating short functional sites in modular eukaryotic proteins. Nucleic acids research 2003, 3 I (I3):3625-3630.

99. Neduva V, Linding R, Su-Angrand I, Stark A, de Masi F, Gibson T], Lewis J, Serrano L, Russell RB: Systematic discovery of new recognition peptides mediating protein interaction networks. PLoS biology 2005, 3(I 2):e405.

100. Davey NE, Shields DC, Edwards RJ: SLiMDisc: short, linear motif discovery, correcting for common evolutionary descent. Nucleic Acids Res 2006, 34( I 2):3546-3554.

10I. Fuxreiter M, Tompa P, Simon I: Local structural disorder imparts plasticity on linear motifs. Bioinformatics 2007, 23(8):950-956

102. Dyson HJ, Wright PE: Coupling of folding and binding for unstructured proteins. Curr Opin Struct Biol 2002, I 2(I):54-60.

103. Callaghan AJ, Aurikko JP, Ilag LL Gunter Grossmann J, Chandran V Kuhnel K, Poljak L, Carpousis AJ, Robinson CV, Symmons MF, et al.: Studies of the RNA degradosome-organizing domain of the Escherichia coli ribonuclease RNase E. Journal of molecular biology 2004, 340(5):965-979.

104. Bourhis JM, Johansson K, Receveur-Brechot V, Oldfield CJ, Dunker KA, Canard B, Longhi S: The C-terminal domain of measles virus nucleoprotein belongs to the class of intrinsically disordered proteins that fold upon binding to their physiological partner. Virus research 2004, 99(2):157-167.
105. Kingston RL, Hamel DJ, Gay LS, Dahlquist FW, Matthews BW: Structural basis for the attachment of a paramyxoviral polymerase to its template. Proceedings of the National Academy of Sciences of the United States of America 2004, I O I (22):830 I-8306.

106. Fuxreiter M, Simon I, Friedrich P, Tompa P: Preformed structural elements feature in partner recognition by intrinsically unstructured proteins. I Mol Biol 2004, 338(5): I0 I 5- 1026.

107. Schulz GE: Nucleotide binding proteins. In Molecular mechanism of biological recognition Edited by: Balaban M. New York: Elsevier/NorthHolland Biomedical Press; 1979:79-94.

108. Gunasekaran K, Tsai CJ, Nussinov R: Analysis of ordered and disordered protein complexes reveals structural features discriminating between stable and unstable monomers. J Mol Biol 2004, 34 I(5): | 327-|34|

109. Tompa P, Fuxreiter M: Fuzzy complexes: polymorphism and structural disorder in protein-protein interactions. Trends Biochem Sci 2008, 33(I):2-8.

I 10. Lacy ER, Filippov I, Lewis WS, Otieno S, Xiao L, Weiss S, Hengst L, Kriwacki RW: p27 binds cyclin-CDK complexes through a sequential mechanism involving binding-induced protein folding. Nat Struct Mol Biol 2004, I I (4):358-364.

III. Morgan DO: Principles of CDK regulation. Nature 1995 , 374(65 | 8): $13 \mid-134$

1 12. Hengst L, Reed SI: Inhibitors of the Cip/Kip family. Curr Top Microbiol Immunol 1998, 227:25-4I.

II3. Sherr C], Roberts JM: CDK inhibitors: positive and negative regulators of GI-phase progression. Genes Dev 1999, I3(I2): $|50|-15 \mid 2$.

I 14. Hengst L, Reed SI: Translational control of p27Kip I accumulation during the cell cycle. Science 1996, 27 I(5257): |86|-I864.

115. Pagano M, Tam SW, Theodoras AM, Beer-Romero P, Del Sal G, Chau $V$, Yew PR, Draetta GF, Rolfe M: Role of the ubiquitin-proteasome pathway in regulating abundance of the cyclin-dependent kinase inhibitor p27. Science 1995, 269(5224):682-685.

II6. Grimmler M, Wang Y, Mund T, Cilensek Z, Keidel EM, Waddell MB, jakel $\mathrm{H}$, Kullmann M, Kriwacki RW, Hengst L: Cdk-inhibitory activity and stability of p27Kip I are directly regulated by oncogenic tyrosine kinases. Cell 2007, I 28(2):269-280.

II7. Bloom J, Pagano M, Ababou M, Dutertre S, Lecluse Y, Onclercq R: Deregulated degradation of the cdk inhibitor p27 and malignant transformation ATM-dependent phosphorylation and accumulation of endogenous BLM protein in response to ionizing radiation; a comparison of cell cycle markers in welldifferentiated lobular and ductal carcinomas MNNG-transformed Bloom syndrome B-lymphoblastoids for the detection of Hodgkin's lymphoma-associated antigen in 2D Westerns. Semin Cancer Biol 2003, I3:4I-47.

I 8. Russo AA, Jeffrey PD, Patten AK, Massague J, Pavletich NP: Crystal structure of the p27Kip I cyclin-dependent-kinase inhibitor bound to the cyclin A-Cdk2 complex. Nature 1996, 382(6589):325-33।.

I19. Dunker AK, Uversky VN: Signal transduction via unstructured protein conduits. Nature Chemical Biology 2008, 4(4):229-230.

120. Han JD, Bertin N, Hao T, Goldberg DS, Berriz GF, Zhang LV, Dupuy D, Walhout AJ, Cusick ME, Roth FP, et al.: Evidence for dynamically organized modularity in the yeast protein-protein interaction network. Nature 2004, 430(6995):88-93.

121. Jansen R, Yu H, Greenbaum D, Kluger Y, Krogan NJ, Chung S, Emili A, Snyder M, Greenblatt JF, Gerstein M: A Bayesian networks approach for predicting protein-protein interactions from genomic data. Science (New York, NY) 2003, 302(5644):449-453.

122. Rhodes DR, Tomlins SA, Varambally S, Mahavisno V, Barrette T, Kalyana-Sundaram S, Ghosh D, Pandey A, Chinnaiyan AM: Probabilistic model of the human protein-protein interaction network. Nature biotechnology 2005, 23(8):95I-959.

123. Hasty J, Collins J]: Protein interactions. Unspinning the web. Nature 200I, 4 I I (6833):30-3I.

124. Jeong $\mathrm{H}$, Mason SP, Barabasi AL, Oltvai ZN: Lethality and centrality in protein networks. Nature 200I, 4 I I (6833): 4 I-42.

125. Meador WE, Means AR, Quiocho FA: Modulation of calmodulin plasticity in molecular recognition on the basis of $x$-ray structures. Science 1993, 262(5|40): $17|8-172|$

126. Kriwacki RW, Hengst L, Tennant L, Reed SI, Wright PE: Structural studies of p2IWafl/CipI/Sdil in the free and Cdk2-bound state: conformational disorder mediates binding diversity. Proc Natl Acad Sci USA 1996, 93(2 I): I I 504-I I 509. 
I27. Dunker AK, Cortese MS, Romero P, lakoucheva LM, Uversky VN: Flexible nets. The roles of intrinsic disorder in protein interaction networks. The FEBS journal 2005, 272(20):5|29-5 | 48.

128. Bustos DM, Iglesias AA: Intrinsic disorder is a key characteristic in partners that bind $\mathbf{| 4 - 3 - 3}$ proteins. Proteins 2006, 63(I):35-42.

129. Radivojac P, Vucetic S, O'Connor TR, Uversky VN, Obradovic Z, Dunker AK: Calmodulin signaling: analysis and prediction of a disorder-dependent molecular recognition. Proteins 2006 , 63(2):398-4I0.

130. Patil A, Nakamura H: Disordered domains and high surface charge confer hubs with the ability to interact with multiple proteins in interaction networks. FEBS letters 2006 , 580(8):204l-2045.

131. Ekman D, Light S, Bjorklund AK, Elofsson A: What properties characterize the hub proteins of the protein-protein interaction network of Saccharomyces cerevisiae? Genome biology 2006, 7(6):R45

132. Haynes C, Oldfield CJ, Ji F, Klitgord N, Cusick ME, Radivojac P, Uversky VN, Vidal M, lakoucheva LM: Intrinsic disorder is a common feature of hub proteins from four eukaryotic interactomes. PLoS computational biology 2006, 2(8):el00.

33. Dosztanyi Z, Chen J, Dunker AK, Simon I, Tompa P: Disorder and sequence repeats in hub proteins and their implications for network evolution. Journal of proteome research 2006 , 5( I I ):2985-2995

134. Singh GP, Dash D: Intrinsic disorder in yeast transcriptional regulatory network. Proteins 2007, 68(3):602-605.

135. Connolly ML: The molecular surface package. Journal of molecular graphics 1993, I I(2): | 39-|4|.

36. Eisenhaber F, Lijnzaad P, Argos P, Sander C, Scharf M: The Double Cubic Lattice Method - Efficient Approaches to NumericalIntegration of Surface-Area and Volume and to Dot Surface Contouring of Molecular Assemblies. J Comput Chem 1995, I 6(3):273-284.

137. Jones S, Thornton JM: Analysis of protein-protein interaction sites using surface patches. Journal of molecular biology 1997, 272(I): $|2|-\mid 32$.

138. Koshland DE Jr, Ray WJ Jr, Erwin MJ: Protein structure and enzyme action. Fed Proc 1958, I 7(4): I |45-II 50.

139. Sambrook J: Adenovirus amazes at Cold Spring Harbor. Nature 1977, 268(56 | 6): I0I-104.

140. Black DL: Mechanisms of alternative pre-messenger RNA splicing. Annual review of biochemistry 2003, 72:291-336.

14I. Gilbert W: Why genes in pieces? Nature 1978, 27 I(5645):50 I.

142. Ast G: How did alternative splicing evolve? Nat Rev Genet 2004 5( I 0):773-782.

43. Stamm S, Ben-Ari S, Rafalska I, Tang Y, Zhang Z, Toiber D, Thanara TA, Soreq H: Function of alternative splicing. Gene 2005, 344: $1-20$.

[44. Brett D, Hanke J, Lehmann G, Haase S, Delbruck S, Krueger S, Reich J, Bork P: EST comparison indicates $38 \%$ of human mRNAs contain possible alternative splice forms. FEBS letters 2000 , 474(I):83-86

145. Johnson JM, Castle J, Garrett-Engele P, Kan Z, Loerch PM, Armour CD, Santos R, Schadt EE, Stoughton R, Shoemaker DD: Genomewide survey of human alternative pre-mRNA splicing with exon junction microarrays. Science (New York, NY) 2003 , 302(5653):2|4|-2|44.

146. Graveley BR: Alternative splicing: increasing diversity in the proteomic world. Trends Genet 200I, I7(2):100-107.

I47. Minneman KP: Splice variants of $\mathbf{G}$ protein-coupled receptors. Molecular interventions 200 I, I(2): I08-I I6.

148. Thai TH, Kearney JF: Distinct and opposite activities of human terminal deoxynucleotidyltransferase splice variants. J Immunol 2004, I 73(6):4009-40I9.

149. Scheper W, Zwart R, Baas F: Alternative splicing in the N-terminus of Alzheimer's presenilin I. Neurogenetics 2004, 5(4):223-227.

150. Roberts R, Timchenko NA, Miller JW, Reddy S, Caskey CT, Swanson MS, Timchenko LT: Altered phosphorylation and intracellular distribution of a (CUG)n triplet repeat RNA-binding protein in patients with myotonic dystrophy and in myotonin protein kinase knockout mice. Proceedings of the National Academy of Sciences of the United States of America 1997, 94(24): | $3221-13226$.
I5I. Ma K, Inglis JD, Sharkey A, Bickmore WA, Hill RE, Prosser EJ, Speed RM, Thomson EJ, Jobling M, Taylor K, et al.: A Y chromosome gene family with RNA-binding protein homology: candidates for the azoospermia factor AZF controlling human spermatogenesis. Cell I993, 75(7): I287-1295.

152. Lovestone S, Reynolds CH, Latimer D, Davis DR, Anderton BH, Gallo JM, Hanger D, Mulot S, Marquardt B, Stabel S, et al:: Alzheimer's disease-like phosphorylation of the microtubule-associated protein tau by glycogen synthase kinase-3 in transfected mammalian cells. Curr Biol 1994, 4(I 2): 1077-1086.

153. Venables JP: Aberrant and alternative splicing in cancer. Cancer research 2004, 64(2I):7647-7654.

I54. Wang P, Yan B, Guo JT, Hicks C, Xu Y: Structural genomics analysis of alternative splicing and application to isoform structure modeling. Proceedings of the National Academy of Sciences of the United States of America 2005, I 02(52): I8920-I8925.

155. Furnham N, Ruffle S, Southan C: Splice variants: a homology modeling approach. Proteins 2004, 54(3):596-608.

I56. Le Gall T, Romero PR, Cortese MS, Uversky VN, Dunker AK: Intrinsic disorder in the Protein Data Bank. J Biomol Struct Dyn 2007. 24(4):325-342.

157. Oakley AJ, Harnnoi T, Udomsinprasert R, Jirajaroenrat K, Ketterman Al, Wilce MC: The crystal structures of glutathione S-transferases isozymes I-3 and I-4 from Anopheles dirus species B. Protein Sci 200I, I O(I I):2I 76-2I85.

158. Hymowitz SG, Compaan DM, Yan M, Wallweber HI, Dixit VM, Starovasnik MA, de Vos AM: The crystal structures of EDA-AI and EDA-A2: splice variants with distinct receptor specificity. Structure 2003, I I(I 2): I5 I3-1520.

159. Peneff C, Ferrari P, Charrier V, Taburet Y, Monnier C, Zamboni V, Winter I, Harnois M, Fassy F, Bourne $Y$ : Crystal structures of two human pyrophosphorylase isoforms in complexes with UDPGIc(Gal)NAc: role of the alternatively spliced insert in the enzyme oligomeric assembly and active site architecture. The EMBO journal 200I, 20(22):6191-6202.

160. Lee KA, Fuda H, Lee YC, Negishi M, Strott CA, Pedersen LC: Crystal structure of human cholesterol sulfotransferase (SULT2BIb) in the presence of pregnenolone and 3'-phosphoadenosine 5'-phosphate. Rationale for specificity differences between prototypical SULT2AI and the SULT2BG I isoforms. The Journal of biological chemistry 2003, 278(45):44593-44599.

16I. Fiegen D, Haeusler LC, Blumenstein L, Herbrand U, Dvorsky R, Vetter IR, Ahmadian MR: Alternative splicing of Racl generates Rac I b, a self-activating GTPase. The Journal of biological chemistry 2004, 279(6):4743-4749.

162. Apic G, Gough J, Teichmann SA: Domain combinations in archaeal, eubacterial and eukaryotic proteomes. I $\mathrm{Mol} B i o$ 200I, 3 I 0(2):3II -325.

163. Wetlaufer DB: Nucleation, rapid folding, and globular intrachain regions in proteins. Proc Natl Acad Sci USA 1973 70(3):697-70l.

164. Richardson JS: The anatomy and taxonomy of protein structure. Adv Protein Chem 1981, 34:167-339.

165. Bork P: Shuffled domains in extracellular proteins. FEBS Lett I991, 286(I-2):47-54

166. Chothia C: Proteins. One thousand families for the molecular biologist. Nature 1992, 357(6379):543-544.

167. Mulder NJ, Apweiler R, Attwood TK, Bairoch A, Bateman A, Binns D, Biswas M, Bradley $P$, Bork $P$, Bucher $P$, et al.: InterPro: an integrated documentation resource for protein families, domains and functional sites. Brief Bioinform 2002, 3(3):225-235.

168. Dunker AK, Obradovic Z, Romero P, Garner EC, Brown CJ: Intrinsic protein disorder in complete genomes. Genome Inform Ser Workshop Genome Inform 2000, I I: I6I-I7I.

169. Estrada E: Virtual identification of essential proteins within the protein interaction network of yeast. Proteomics 2006, 6(I):35-40.

170. Drews ]: Drug discovery: a historical perspective. Science (New York, NY) 2000, 287(5460): I 960-1964

17I. Cochran AG: Antagonists of protein-protein interactions. Chemistry \& biology 2000, 7(4):R85-94

172. Arkin M: Protein-protein interactions and cancer: small molecules going in for the kill. Current opinion in chemical biology 2005, 9(3):317-324. 


$\begin{array}{lc}\text { Drug Discov } & \text { Nat Rev } \\ \text { Mol Cancer Res } & \text { Nature } \\ \text { Curr Biol } & \text { Cell cycle (Geor- } \\ \text { getown, Tex) } & \text { Journal of molec- } \\ \text { ular biology } & \end{array}$

Publish with Biomed Central and every scientist can read your work free of charge

"BioMed Central will be the most significant development for disseminating the results of biomedical research in our lifetime. " Sir Paul Nurse, Cancer Research UK

Your research papers will be:

- available free of charge to the entire biomedical community

- peer reviewed and published immediately upon acceptance

- cited in PubMed and archived on PubMed Central

- yours - you keep the copyright 